\title{
Development of Phenomenological
} Models of Underground Nuclear Tests on Pahute Mesa, Nevada Test SiteBENHAM and TYBO

\author{
Gayle A. Pawloski
}

September 21, 1999

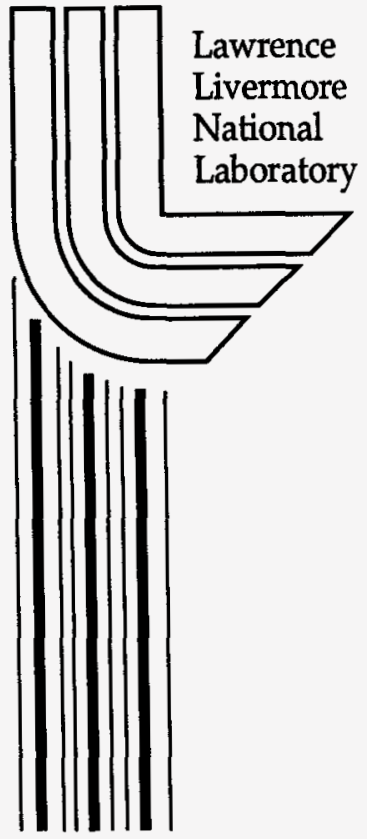




\section{DISCLAIMER}

This document was prepared as an account of work sponsored by an agency of the United States Government. Neither the United States Government nor the University of California nor any of their employees, makes any warranty, express or implied, or assumes any legal liability or responsibility for the accuracy, completeness, or usefulness of any information, apparatus, product, or process disclosed, or represents that its use would not infringe privately owned rights. Reference herein to any specific commercial product, process, or service by trade name, trademark, manufacturer, or otherwise, does not necessarily constitute or imply its endorsement, recommendation, or favoring by the United States Government or the University of California. The views and opinions of authors expressed herein do not necessarily state or reflect those of the United States Government or the University of California, and shall not be used for advertising or product endorsement purposes.

This work was performed under the auspices of the U.S. Department of Energy by the University of California, Lawrence Livermore National Laboratory under Contract No. W-7405-Eng-48.

Available for sale to the public from-

U.S. Department of Commerce

National Technical Information Service

5285 Port Royal Road

Springfield, VA 22161

Phone: 800.553 .6847

Fax: 703.605.6900

Email: orders@ntis.fedworld.gov

Online ordering: http://www.ntis.gov/ordering.htm

Available electronically at http://www.doe.gov/bridge

Available for a processing fee to U.S. Department of Energy and its

contractors, in paper, from-

U.S. Department of Energy

Office of Scientific and Technical Information

P.O. Box 62

Oak Ridge, TN 37831-0062

Phone: 865.576 .8401

Fax: 865.576.5728

Email: reports@adonis.osti.gov

OR

Lawrence Livermore National Laboratory

Technical Information Department's Digital Library

http://www.llnl.gov/tid/Library.html 


\section{Development of Phenomenological Models of Underground Nuclear Tests on Pahute Mesa, Nevada Test Site- BENHAM and TYBO}

Gayle A. Pawloski

September 21, 1999 



\section{Contents}

1.0 Introduction

1.1 Objective 1

1.2 Assumptions 1

2.0 Generalized Description of Nuclear Explosion Phenomenology 3

2.1 Early-Time Phenomenology 4

2.2 Late-Time Phenomenology 4

2.3 Other Phenomena 5

2.4 Radionuclide Distribution 5

2.5 Phenomenology Discussion 5

3.0 Evaluation of Site-Specific Information for BENHAM : 9

3.1 Background 9

3.2 Hole Construction 9

3.3 Nearby Features 11

3.3.1 Nearby Holes 11

3.3.2 Nearby Surface Effects 12

3.4 Working-Point Medium Properties 12

3.5 Stemming and Emplacement 12

3.6 Downhole Diagnostics 12

3.7 Surface Experiments 12

3.8 Predicted Phenomenology 13

3.9 Photos 13

3.10 Post-Test Drilling 13

3.11 Phenomenology 13

3.11.1 Ground Motion 13

3.11.2 Collapse 16

3.12 Recent Calculations 17

4.0 Evaluation of Site-Specific Information for TYBO 19

4.1 Background 19

4.2 Hole Construction 19

4.3 Nearby Features 20

4.3.1 Nearby Holes 20

4.3.2 Nearby Surface Effects 20 
4.4 Working-Point Medium Properties 20

4.5 Stemming and Emplacement 22

4.6 Downhole Diagnostics 22

4.7 Surface Experiments 22

4.8 Predicted Phenomenology 22

4.9 Photos 22

4.10 Post-Test Drilling 22

4.11 Phenomenology 25

4.11.1 Ground Motion 25

4.11.2 Collapse 25

4.12 Calculations after the Test 30

5.0 Evaluation of Generalized Containment Data

for Phenomenological Models 31

5.1 Regions of the Phenomenological Model 31

5.1.1 Puddle Glass Region 31

5.1.2 Cavity Region 31

5.1.3 Shock-Damaged Region 32

5.1.4 Collapse Chimney Region 33

5.2 Permeability 34

5.3 Injection of Radionuclide Material outside the Cavity Region 35

5.4 Evaluation Conclusions $\quad 35$

6.0 Phenomenological Model as Input for Groundwater Modeling 38

$\begin{array}{lll}6.1 & \text { BENHAM } & 38\end{array}$

6.2 TYBO 38

$\begin{array}{lll}7.0 & \text { References } & 42\end{array}$

8.0 Acknowledgements $\quad 46$ 


\subsection{Introduction}

\subsection{Objective}

Although it is well accepted that underground nuclear explosions modify the in situ geologic media around the explosion point, the details of these changes are neither well understood nor well documented. As part of the engineering and containment process before a nuclear test, the physical environment is characterized to some extent to predict how the explosion will interact with the in situ media. However, a more detailed characterization of the physical environment surrounding an expended site is needed to successfully model radionuclide transport in the groundwater away from the detonation point. It is important to understand how the media have been altered and where the radionuclides are deposited. Once understood, this information on modified geologic media can be incorporated into a phenomenological model that is suitable for input to computer simulations of groundwater flow and radionuclide transport.

The primary goals of this study are to (1) identify the modification of the media at a pertinent scale, and (2) provide this information to researchers modeling radionuclide transport in groundwater for the U.S. Department of Energy (DOE) Nevada Operations Office Underground Test Area (UGTA) Project. Results from this study are most applicable at nearfield scale (a model domain of about $500 \mathrm{~m}$ ) and intermediate-field scale (a model domain of about $5 \mathrm{~km}$ ) for which detailed information can be maximized as it is incorporated in the modeling grids.

UGTA collected data on radionuclides in groundwater during recent drilling at the ER-20-5 site, which is near BENHAM and TYBO on Pahute Mesa at the Nevada Test Site (NTS) (US DOE, 1997 and Kersting et al., 1999) (Figure 1). Computer simulations are being performed to better understand radionuclide transport. The objectives of this modeling effort include:

- Evaluating site-specific information from the BENHAM and TYBO tests on Pahute Mesa.

- Augmenting the above data set with generalized containment data.

- Developing a phenomenological model suitable for input to groundwater flow and transport modeling efforts that describes the physical in situ environment after the BENHAM and TYBO nuclear explosions.

In general, these models use validated data rather than anecdotal data to constrain input parameters. Much of these data are from the Lawrence Livermore National Laboratory (LLNL), Defense and Nuclear Technologies Directorate, Containment Program. The identification and distribution of radionuclides are not part of this study, but are part of a future study planned by LLNL as we calculate the hydrologic source term for tests on Pahute Mesa.

Phenomenology and containment of underground nuclear explosions deals with material properties, not hydraulic properties as required for groundwater flow and transport modeling. Modelers will need to translate data developed in this report and perform sensitivity analyses to supply realistic constraints to input parameters for their codes.

\subsection{Assumptions}

Although much of the following discussion on phenomenology is generalized, the discussion and conclusions of this report apply to nuclear explosions emplaced underground at Pahute Mesa in layered volcanic rocks. Information from Rainier Mesa is also applicable because of the similar geologic environment. Explosions are assumed to be coupled with the media. Pre-explosion vertical fractures are a dominant feature, leading to fracture flow of groundwater rather than porous flow. 


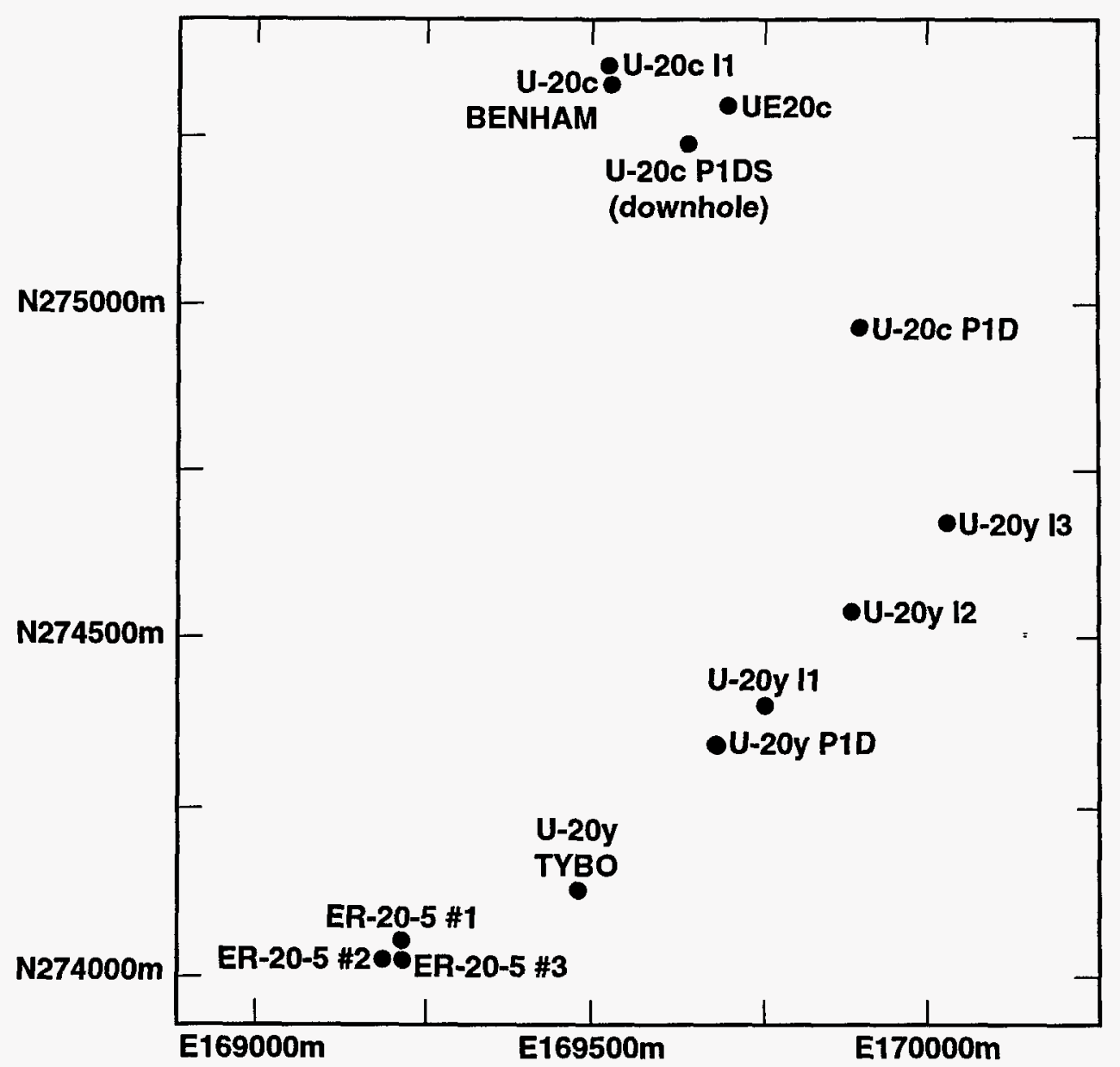

Figure 1. Location of BENHAM and TYBO and selected drill holes on Pahute Mesa. 


\subsection{Generalized Description of Nuclear Explosion Phenomenology}

Phenomenology describes the effects of a nuclear explosion on the surrounding media. The time period from the explosion to when the cavity void grows to its full size and then rebounds is referred to as "early-time phenomenology." These actions are shock induced and include shock compression followed by adiabatic expansion of gas.

Within a few seconds of the explosion, the cavity stabilizes and dynamic motion ceases. The cavity reaches its final size after rebound has occurred, which depends on rock strength. Final cavity pressure does not depend on overburden pressure, but rather on the strength of the overlying rock. Frequently, cavity growth ceases when ambient hydrostatic overpressure is greater than cavity pressure. Actions that occur after the cavity has reached its full size are referred to as "late-time phenomenology," and consist mainly of thermally induced mechanisms that lead to the eventual collapse of the cavity.

Several noted papers have been written on the phenomenology of underground nuclear explosions, including Germain and Kahn, 1968; Butkovich and Lewis, 1973; Butkovich, 1976; and the U.S. Congress/OTA, 1989. The following description is derived from these papers. Generalized cavity growth and collapse for an underground nuclear test are shown in Figure 2.

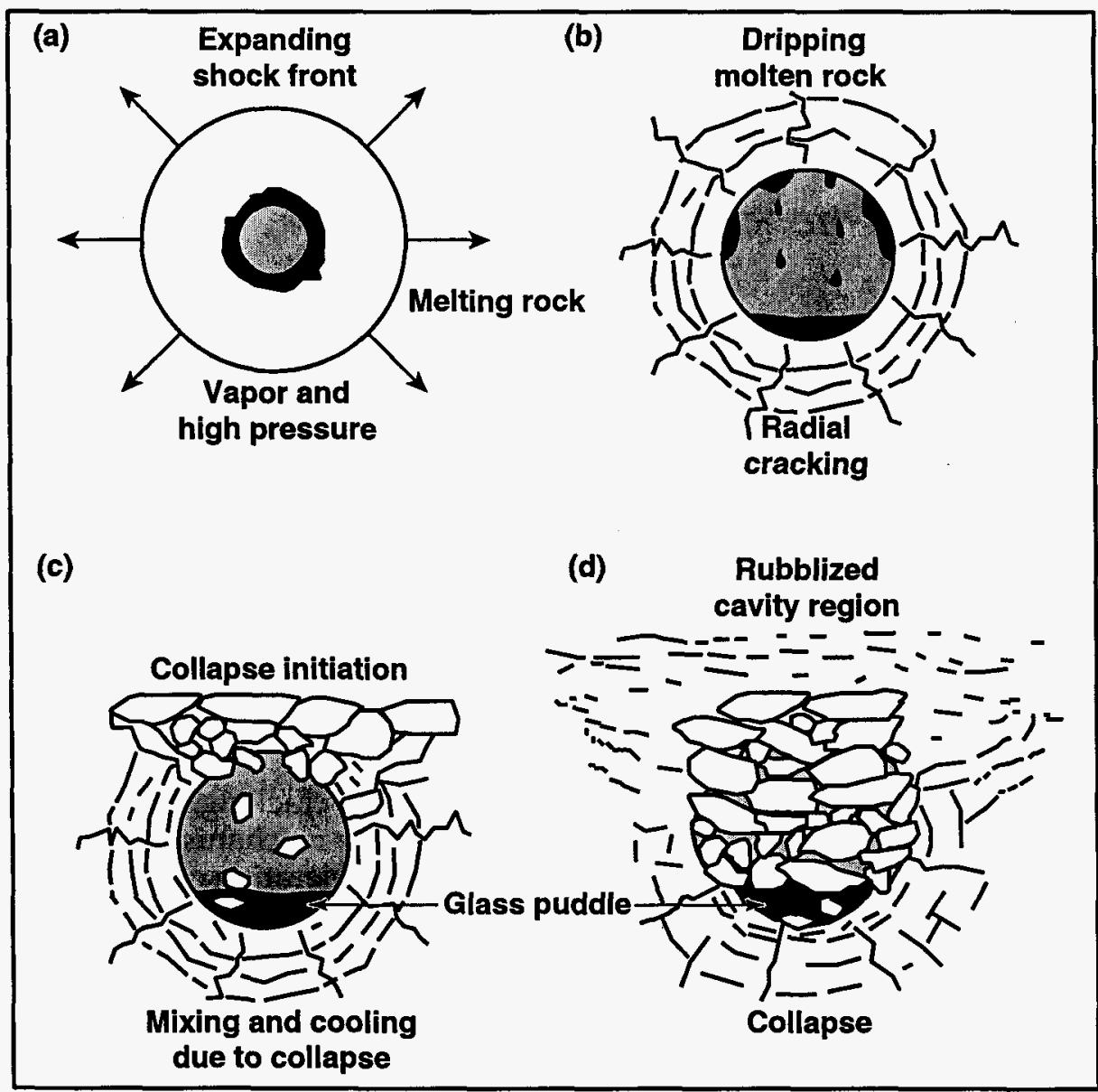

Figure 2. Generalized cavity growth and collapse for an underground nuclear test. 


\subsection{Early-Time Phenomenology}

When an underground nuclear device is exploded, sufficient energy is released to instantaneously vaporize the experiment canister and the rock surrounding the experiment. Initial temperatures rise to several million degrees kelvin and pressures of about 1 megabar are created. As a result, a compressive, outward-moving shock wave is generated. Within microseconds, the energy melts the rock, and within milliseconds it crushes and cracks additional rock. Within tenths of seconds, the energy passes elastically through the outlying material to the surface.

As the rock material surrounding the explosion is vaporized and melted, pore water is also vaporized. The cavity void continues to grow radially as the expanding shock wave imparts outward momentum on the surrounding media. Depending on the yield of the explosion, the cavity reaches its largest size within 80 to $500 \mathrm{~ms}$ when the elastic strains within the rock attempt to recover. Elastic unloading causes the material to rebound radially and try to return to its original position. A compressive tangential hoop stress is formed when the stress field in the rebounded rock is greater than the cavity pressure. This compressive or "residual hoop stress" closes radial fractures that were opened during cavity expansion. The final size of the cavity depends on the yield of the explosion, the overburden stresses, and the strength of the surrounding rock.

As the shock wave moves outward, cavity growth slows. At about one-third of the distance up the drill hole, the shock wave becomes elastic and travels at elastic speeds until it reaches the ground surface, usually within 100 to $500 \mathrm{~ms}$. Along the way, rock failure can be brittle or plastic, depending on the stress conditions and the strength properties of the geologic materials. Upward acceleration of material from the detonation point to the ground surface can cause surface bulges of about 1-3 m. A compressive wave reflected off the ground surface is known as a "rarefaction." Residual stress usually forms before the rarefaction returns to the cavity region.

\section{$2.2 \quad$ Late-Time Phenomenology}

After the shock and elastic waves have dissipated, rock vapor begins to condense and form a puddle of melted material at the bottom of the cavity. Water vapor and noncondensable gases (such as $\mathrm{CO}_{2}$ and $\mathrm{H}_{2}$ ) are still present in the cavity. Within minutes to hours after detonation, energy in the gas is radiated, and high thermal gradients are created within the cavity walls via thermal conduction. This causes ablation and spalling of wall material, and lowers cavity temperatures so that the steam condenses. Flaked wall materials of various sizes increase cooling and mix with the puddle glass; some of these wall materials are incorporated in the melt and larger pieces survive as rubble within the glass material. The repeated ablation and mixing reduces cavity pressure until pressures of only a few pounds per square inch exist. Cavity collapse can start within minutes or hours of the explosion and progresses quickly, usually within tens of minutes. If the overlying rock is not strong enough to support the cavity roof span, collapse propagates upwards. If the material strength of the overlying support is insufficient, collapse can proceed to the surface and form a crater.

Surface ground motion, such as uplift, spall, slapdown, ground cracking, block movement, and compaction, can be caused by shock wave effects or secondary mechanisms, such as fault movement or collapse. Surface bulges can be caused by the acceleration of the ground surface from the outgoing shock wave. Spall occurs down to depths at which rarefaction tensile stress exceeds the ascending compressive wave stress plus the overburden stress and the tensile strength of the rock. Layers of rock can separate or part along naturally occurring planes of weakness. Slapdown, also known as spall closure, occurs when the ground surface free falls after the upward traveling compressive wave accelerates the ground surface. Ground surface cracking and other explosion-caused surface effects are due to the radial divergence of the 
surface from spall motion and preferential movement along preexisting structures (faults, joints, etc.), bulking and compaction resulting from collapse, and spall or rock falls at free surfaces.

\subsection{Other Phenomena}

The early- and late-time phenomenology described above are generalized. Other phenomena can occur, including:

- Hydrofracturing.

- Prompt injection of radionuclides.

- Groundwater effects such as mounding and pressurization.

- Reflections off impedance layers (caused by material property differences, such as rock strength or air void content, bedding planes, and faults).

- Movement on preexisting structural features such as faults.

The above phenomena may affect cavity growth, residual stress, collapse, and crater formation.

\subsection{Radionuclide Distribution}

Radionuclide distribution is affected by the temperature and pressure of the nuclear explosion and thermodynamic evolution through collapse. In general, refractory radionuclides (such as $\mathrm{Pu}$, $\mathrm{Am}, \mathrm{Np}, \mathrm{Ce}$, and $\mathrm{Eu}$ ) with higher boiling points and lower vapor pressures are incorporated lower in the cavity, and lower boiling point radionuclides (such as $\mathrm{Sr}$ and $\mathrm{Cs}$ ) with higher vapor pressure can travel farther due to their volatility. Refractory radionuclides are almost entirely incorporated in the puddle glass and fused melt debris at the base of the cavity and at the perimeter of the cavity. Remaining radionuclides are heterogeneously distributed in the cavity rubble by volatilization, condensation, and collapse. Phenomena described in Section 2.3 may permit radionuclides to travel outside the cavity; these phenomena are discussed later in this report. Additional information on initial radionuclide distribution may be found in Kersting, 1996 and Tompson et al., 1999.

\subsection{Phenomenology Discussion}

The science of the containment of underground nuclear tests has been evolutionary. A combination of theoretical information and diagnostic, post-test, and re-entry data allow us to understand the phenomenology of specific cases and make generalizations.

Data may be derived from many sources:

- Hydrodynamic calculations were performed on selected tests, and they provide a significant amount of theoretical information. Interpretations derived from these include cavity size and pressure, residual stress, zones of failure, and ground motion. These calculations were completed before a test to examine phenomenology and understand risk to nearby equipment and more distant humans and manmade structures. Early calculations were only one dimensional. Layered two-dimensional calculations were developed in the 1970s. Calculations incorporating stemming materials in the drill hole were common in the 1980s. Three-dimensional analyses were rarely made. Post-test calculations were undertaken only to occasionally match data or develop research opportunities.

Early calculations examined the early-time dynamic phase up to the formation of residual stress, and included predictions of tensile failure. Later calculations in the 1980s linked dynamic damage to cavity pressure, permitting hydrofracture calculations and late-time gas flow predications. 
- Post-test activities (drilling, gamma logging, and sampling) permit gross reconstruction of the cavity's physical setting, including distribution of radionuclides and limited information on material composition and texture. Many tests, but not all, had post-test activities. Three cavities have been mined back to permit re-entry (RAINIER, GNOME, and SALMON) and only one-RAINIER - is applicable to this study because the test was sited in tuff at the NTS. Re-entry of Rainier Mesa tunnel sites after nuclear tests has provided the most data concerning measured properties and material distributions in the cavity region (RAINIER test data: Wadman and Richards, 1961; Piwinskii et al., 1983). Re-entry into RED HOT, also in tuff at Rainier Mesa, provided information on the explosion crater and chimney (Townsend, 1994). Recent sampling analysis (Smith, 1995; Thompson, 1998) and gamma log evaluation (Kenneally, 1996) have provided information on radionuclide distribution.

- Cavity size has been predicted by shock wave calculations and measured by post-test drilling and tunnel re-entry mining. We assume the cavity is spherical and grows equally in all directions, although we know this would be true only if the media were homogeneous and no free surface existed (Hudson, 1981). Data and calculations indicate material properties, including rock strength, are intimately involved in cavity growth and residual stress (Terhune and Glenn, 1977; Rimer, 1981). High strength rocks exhibit narrow zones of calculated high residual stress and can induce large amounts of tensile failure. Weak materials may enhance cavity growth and exhibit broad but reduced residual stress and fewer to no radial cracks outside the residual stress region. Cavity shape can be influenced by in situ rock properties and structures near the working point, and can be oblate if constricted (Rambo, 1987).

- The volume of rock vaporized and melted by the shock wave determines the volume of the glass puddle in which most of the radionuclides from a nuclear test are encapsulated. Higgins (1987) suggests that $500 \mathrm{Mg} / \mathrm{kt}$ of saturated tuff are vaporized and melted per ton of nuclear explosive, depending on pressure, temperature, and mixing. Peterson et al. (1991) identify a range of $500-2700 \mathrm{Mg} / \mathrm{kt}$ of rock that is vaporized and melted; quantities vary depending on the amount of coupling to the surrounding media, amount of dynamic mixing, and medium properties. On the basis of tracer gas released in the cavity, $700 \mathrm{Mg} / \mathrm{kt}$ may best represent a volume over which material will intermingle with cavity gas (Olsen, 1993).

- Gas sampling, the antithesis of containment, provides the data necessary to evaluate performance of the test and can give information on composition and distribution of radionuclides. These data are usually classified.

- Collapse evolution can be obtained from cable length information, and roughly interpreted from chimney and crater information. Cable length measurements can be used to identify subsurface collapse height for tests that do not collapse to the surface. Crater size (depth and diameter) has been used to predict chimney shape and volume for tests that collapse to the surface. Routine post-test surveys provide depth and diameter measurements for tests that collapse to the surface.

- Ground motion, measured near site ground zero (SGZ) and recorded by regional seismic arrays, includes full waveform information. Near-field instrumentation can provide surface velocities and displacements.

- Remote area monitoring stations (RAMS) were installed in drill holes and were used to determine pressure and radiation in the stemming column and the effectiveness of plug materials to impede gas flow. These instruments were used sporadically in the 1970s and were more common in the 1980s.

This large cohesive data set permits us to approximate the physical setting, that is the zones affected by the explosion and shock wave, the cavity, chimney, crater, mass of rock, pressures and temperatures, and distribution of radionuclides. There are also exceptions to these generalized descriptions. 
Many but not all containment scientists believe the concept of residual stress and its significance to containment. The formation of residual stress is important because it is thought to close any fractures and ideally contain all radioactive materials close to the cavity. Calculations can show that rebounding rock forms compressive stress within about 2 cavity radii and closes radial fractures (many, including Rambo, 1987). Laboratory tests in grout spheres have measured containing stress greater than measured cavity pressure (Smith, 1981, and Cizek and Florence, 1981a). Cavity pressures have been measured and support the concept of residual stress (Hudson et al., 1993; Smith and Breeze, 1993; Rambo and Rimer, 1993). However, calculations have shown that residual stress does not always form, and containment has been both satisfactory (the BARNWELL test, Rambo and Moss, 1991) and unsatisfactory (the BANEBERRY test, Terhune et al., 1977).

Ideally, residual stress keeps radionuclides within about 2 cavity radii of the explosion point before collapse. Ignoring prompt venting resulting from inadequate stemming methods or emplacement near faults, hydrofracturing is the most likely mechanism to breach residual stress and permit radionuclides to promptly travel away from the cavity. Re-entry mining of Rainier Mesa tunnel tests shows that hydrofracturing occurs, but is limited to about 2 cavity radii from the explosion point. A large number of calculational and laboratory tests have been conducted to investigate the topic of hydrofracturing: Butkovich and Hearst, 1976; Cizek and Florence, 1981b; Kunkle and Travis, 1981; Nilson, 1981; Smith, 1981; Griffiths and Nilson, 1987; Nilson et al., 1987, Rimer et al., 1987; and Nilson et al. 1991. The main conclusions of these studies are that hydrofracturing can occur only when the cavity is growing (when cavity pressure is greater than hydrostatic pressure). Hydrofractures need significant pressure to initiate and then sustain themselves, and steam can drive fractures up to 2 or 3 cavity radii from the explosion point under normal conditions. There are three conclusive cases of prompt injection of radionuclides in Yucca Flat (Nimz and Thompson, 1992). To date none have been noted at Pahute Mesa. This may be simply fortuitous, related to deep burial in fractured volcanic rocks, or wider spacing of emplacement holes on account of larger yields. It is important to note that no systematic investigation of prompt injection has been conducted on Pahute Mesa.

Figure 3 summarizes many one-dimensional hydrodynamic calculations for a single test to show generalized phenomenology for a large, deeply buried nuclear explosion on Pahute Mesa. In this example, the explosion point is at about a $1230-\mathrm{m}$ depth, and the regional water table is located about $630 \mathrm{~m}$ above the explosion point. Cavity growth history and first-wave arrivals for the elastic and plastic waves are shown from the explosion point to the free surface as a function of time. The elastic wave proceeds quickly and directly to the free surface, arriving at about $0.4 \mathrm{~s}$. The plastic wave arrives later, at about $0.55 \mathrm{~s}$, because it is attenuated by the porosity in the rock medium. The plastic wave's path does not proceed directly to the free surface because it is affected by interacting reflections off the layered rocks and the water table. Near-surface spall begins after the plastic wave arrives and extends to a depth of about $200 \mathrm{~m}$. The cavity is almost at full size by $0.5 \mathrm{~s}$. Cavity pressure is very high (about $250 \mathrm{bars}$ ) and degrades to about 40 bars before $1.0 \mathrm{~s}$.

Summarized stress conditions are also plotted on Figure 3. A residual stress is established where tangential hoop compressive stress $\left(\sigma_{\theta}\right)$ is greater than cavity pressure $\left(P_{c}\right)$. Tensile failure may exist where cavity pressure is greater than tangential-hoop compressive stress. If the tensilely failed zones exist when cavity pressure is sufficiently high, then hydrofracturing from the cavity region may occur. When near the cavity edge, hydrofracturing may be considered part of cavity growth or a damaged zone formed within the residual stress field (out to about 2 cavity radii). This example, a large explosion under the water table, shows tensile failure between 0.3 and $0.6 \mathrm{~s}$. A large area of tensile failure caused by rarefactions off the water table occurs just below the water surface and extends to the cavity region. If cavity pressure is sufficiently high at this point in time, hydrofracturing may occur. The distance the hydrofracture may extend depends on the pre-test stress state of the medium, the size of the hydrofracture(s), 
and the sustained cavity pressure. Even if hydrofractures do not form, this region exhibits tensile failure that can be a path for radionuclides away from the cavity region.

It is important to keep in mind the time frames of nuclear explosion phenomenology and radionuclide transport. Cavity growth, and hence hydrofracturing, occur within several hundred milliseconds of the explosion. This is a time of dynamic motion and high temperatures and pressures. Cracks formed during cavity growth remain open until residual stress forms. Rebound, or the formation of residual stress, normally closes radial cracks opened by the explosion. At the end of cavity growth but prior to collapse initiation, it is possible to release radionuclides via open cracks or spall fractures. After collapse (minutes to hours), only porous flow of noncondensable gases is probable.

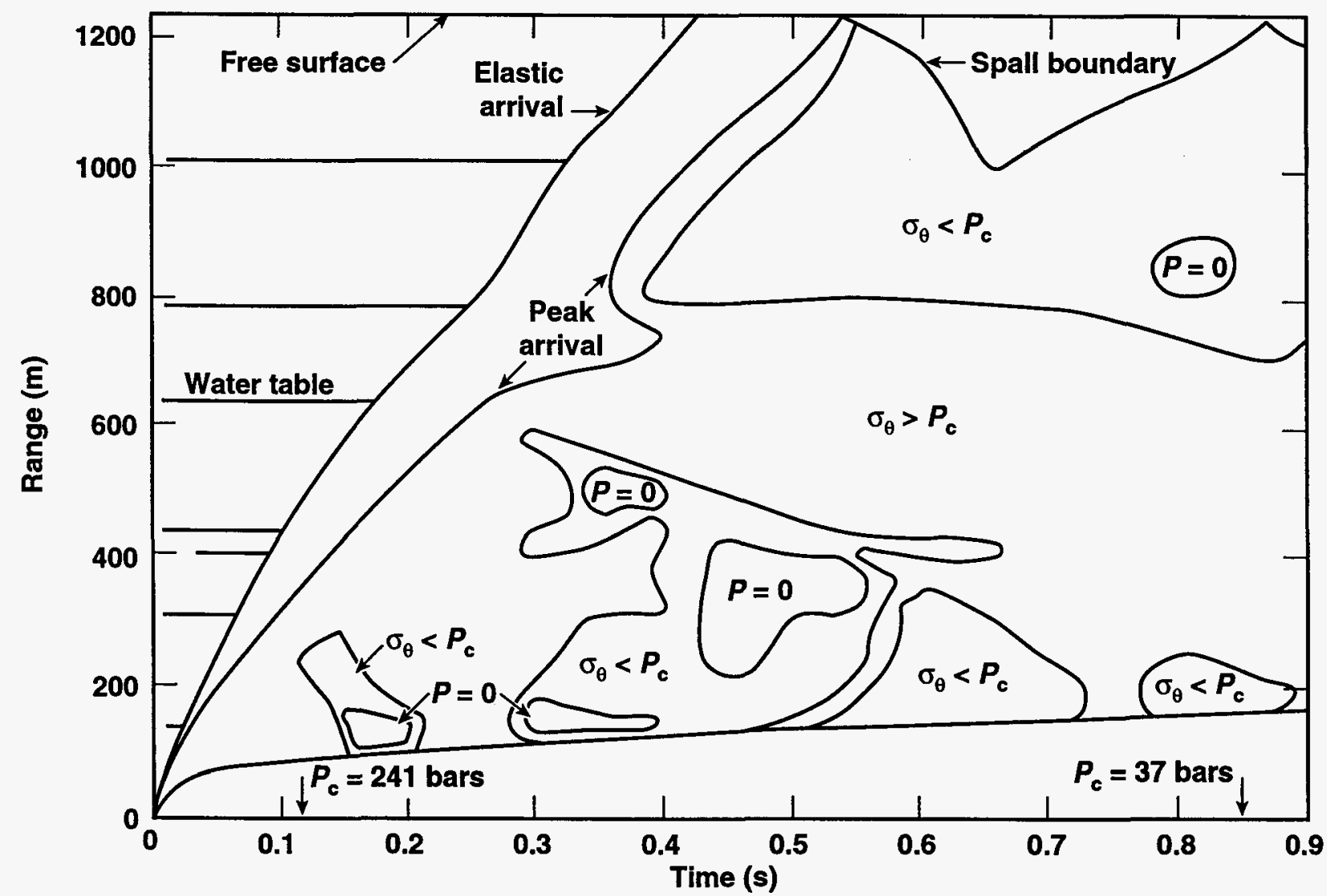

Figure 3. Stress conditions from a summary of one-dimensional shock phenomenology calculations for a high-yield test emplaced below the water table on Pahute Mesa. 


\subsection{Evaluation of Site-Specific Information for BENHAM}

\subsection{Background}

We examined hole construction, experiment emplacement, and post-test data to determine whether modification to the in situ media by the BENHAM test could be recognized. Data sources were mainly informal, including reports, memorandums, photos, laboratory data, hydrodynamic calculations, and discussions with personnel who were involved in fielding the experiments; some of these resources are classified.

The BENHAM test was executed on December 19, 1968, in drill hole U-20c at Pahute Mesa. It was emplaced in a room $(9.1 \times 9.1 \mathrm{~m})$ mined in the shape of an oblate spheroid centered at $1402 \mathrm{~m}$. At the announced official yield of $1.15 \mathrm{Mt}$, BENHAM was one of the larger tests at the NTS (US DOE, 1994).

Because of its size, BENHAM required a location removed from interactions with other tests being fielded on Pahute Mesa during this busy period of underground nuclear testing. The high yield required a deep working point for containment, and thus a location below the water table was mandated. U-20 c was drilled for the BENHAM test in southern Pahute Mesa where no previous testing had occurred. The working point was located in a formation that (1) consisted of rock strong enough to stay open after mining, but could still be mined without difficulty, and (2) did not produce enough water to impact mining operations. After drilling and geophysical logging, the working point was further refined to place it below a sharp break in velocity and density data at $1180 \mathrm{~m}$ so that the experimenters would have the $122 \mathrm{~m}$ of homogeneous media required for their tests.

Prothro and Warren (1999) recently updated stratigraphic and lithologic logs in support of UGTA modeling near BENHAM and TYBO. Contacts and descriptions show only minor differences in interpretations from work at the time of the BENHAM test.

\subsection{Hole Construction}

U-20c, at 1.83-m diam, was drilled to a total depth of $1463.04 \mathrm{~m}$ from June 26, 1964 to May 13, 1965. Work on the hole was suspended for almost one year (from April 6, 1965 to February 14, 1966) after the total depth was reached but before the casing was set. A temperature $\log$ was run on re-entering the hole on March 2, 1966; this $\log$ went to $1462.4 \mathrm{~m}$, indicating that the drill hole was stable over the suspension time. There was little fill while drilling and only minor problems typical for drilling deep holes (e.g., UE-20d and UE-20f) at this time on Pahute Mesa. A 1.22-m-diam casing was emplaced from the surface to $1449.3 \mathrm{~m}$. Geologic samples from the hole include cuttings over the total depth of the hole and six conventional cores at selected depths from 1386.5 to $1463.0 \mathrm{~m}$. Geophysical logs were run in the hole. Stereo photographs (called XY photos) were taken at selected locations when the hole was completed. Geologic and geophysical data from the drill hole appear typical for the formations penetrated. Geologic structure is simple, as shown in the cross section in Figure 4 (US DOE, 1997).

A room $(9.1 \times 9.1 \mathrm{~m})$ was mined from 1399.6 to $1404.2 \mathrm{~m}$ from March 9, 1967 to August 6,1968 . The room, lined with steel and cement, was connected to the drill-hole casing for water control.

Damp cuttings were first noted at $620.6 \mathrm{~m}$, and 138 gal per minute (gpm) of water was recovered from the drill hole at $637.0 \mathrm{~m}$. Water production of about $65 \mathrm{gpm}$ was obtained 

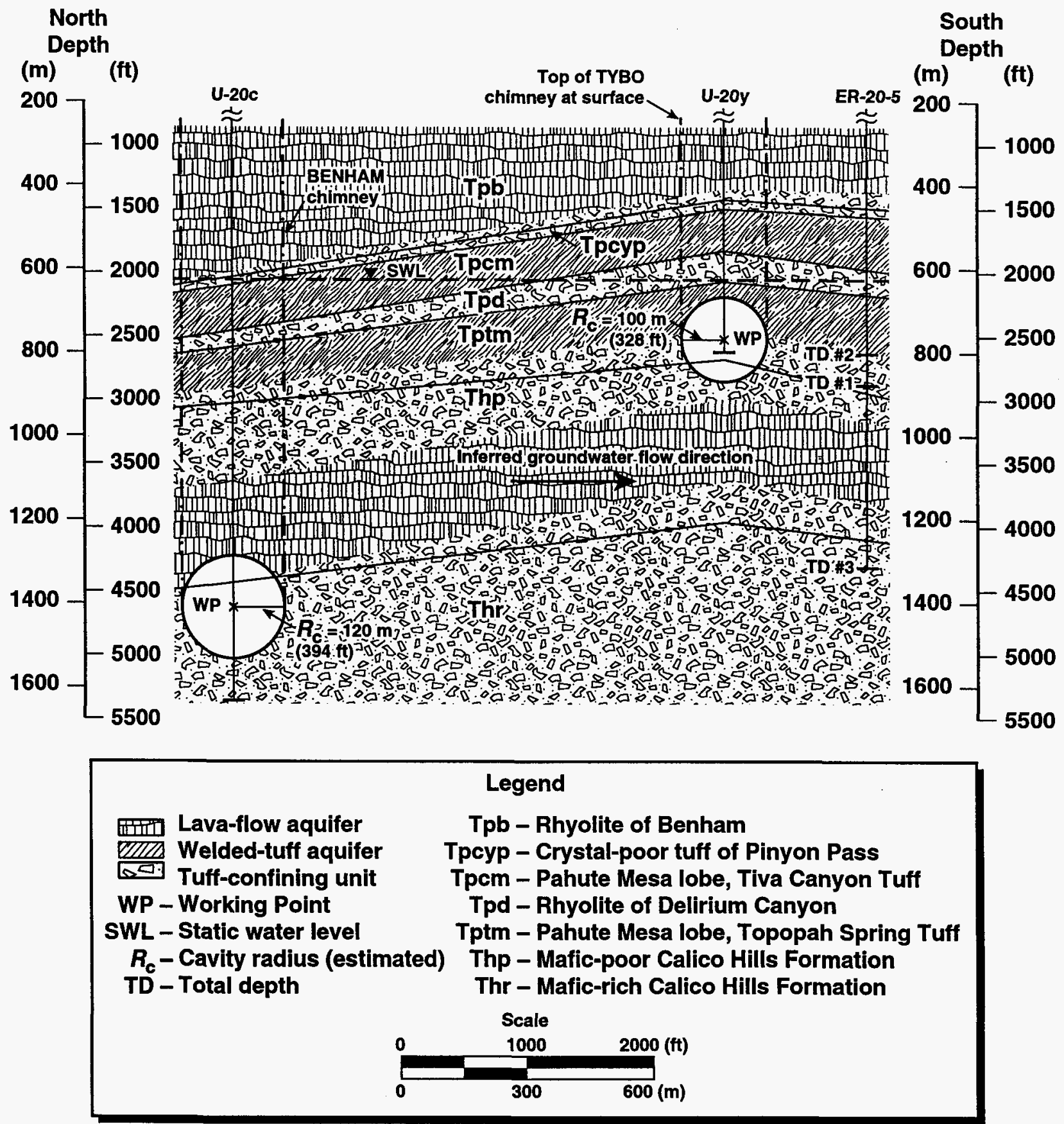

Adapted from: Completion Report for Well Cluster ER-20-5, DOE/NV-466

Figure 4. Cross section between U-20c, U-20y, and ER-20-5 drill holes. 


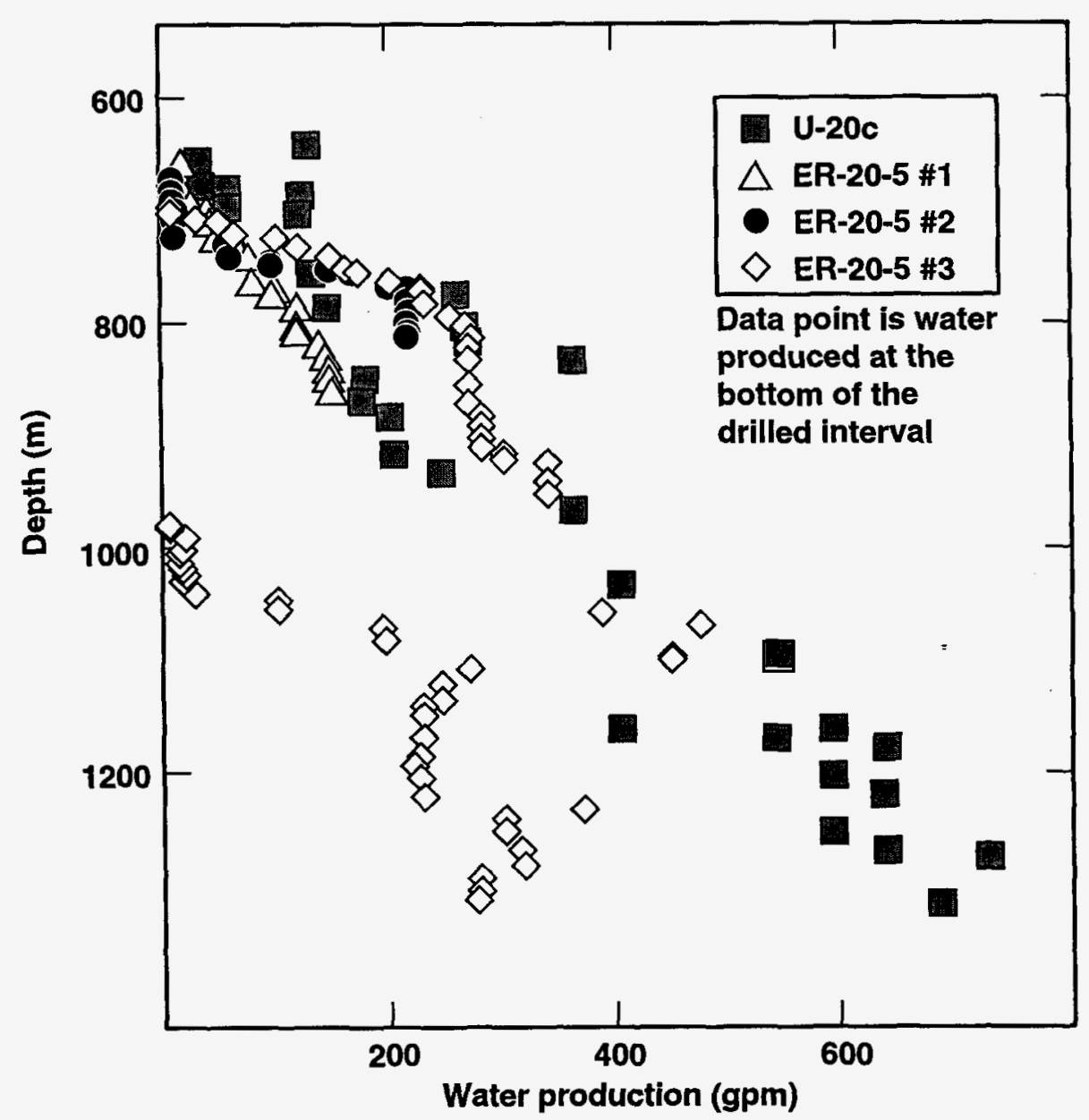

Figure 5. Water production at U-20c and ER-20-5 drill holes.

below $670.6 \mathrm{~m}$; 200 gpm below $864.4 \mathrm{~m}$; greater than 500 gpm below $1064.1 \mathrm{~m}$; and greater than $600 \mathrm{gpm}$ from $1167.4 \mathrm{~m}$ to $1289.3 \mathrm{~m}$. Figure 5 shows similar water production rates for U-20c and the ER-20-5 holes. The aquifers penetrated by these holes should be considered continuous with similar hydraulic properties. Static water level was determined to be $640.1 \mathrm{~m}$. Temperatures of $120-121^{\circ} \mathrm{F}$ were recorded at $1402.1 \mathrm{~m}$ after construction of the mined room.

\subsection{Nearby Features}

\subsubsection{Nearby Holes}

There were two holes associated with emplacement hole U-20c. UE-20c was drilled as an exploratory hole before the emplacement hole was begun. It was drilled to $1630.1 \mathrm{~m}$ from February 6, 1964 to April 11, 1964. Hydrologic tests were planned for this hole; however, because of construction problems, the hole was plugged with cement and abandoned before the tests occurred. U-20 I1, located $30.5 \mathrm{~m}$ north of the emplacement hole, was drilled to $1431.3 \mathrm{~m}$ for hydrodynamic yield measurements; this hole was immediately instrumented and then grouted to the surface. 


\subsubsection{Nearby Surface Effects}

Since BENHAM was the first test in this locality, no test-related surface features were present before BENHAM was detonated.

\subsection{Working-Point Medium Properties}

The working point for BENHAM was at $1402 \mathrm{~m}$ in a zeolitized bedded tuff of the mafic-rich Calico Hills Formation, with sparse pumice and lithics overlain by a rhyolite lava. Sparse medium property data were derived from geophysical logs and measurements on cores from other exploratory holes on Pahute Mesa. Averaged medium properties are summarized in Table 1.

Table 1. Averaged medium properties for selected zones at BENHAM.

\begin{tabular}{l|c|c|c|c|c}
\hline Property & $\begin{array}{c}\text { Working } \\
\text { point } \\
(1402 \mathrm{~m})\end{array}$ & Overburden & $\begin{array}{c}\text { Zeolitized } \\
\text { bedded tuff } \\
\text { (working- } \\
\text { point area) }\end{array}$ & $\begin{array}{c}\text { Rhyolite lava } \\
\text { (above } \\
\text { working point) }\end{array}$ & $\begin{array}{c}\text { Zeolitized } \\
\text { bedded tuff } \\
\text { (above lava) }\end{array}$ \\
\hline \hline Gas porosity (\%) & 0.0 & & & & \\
\hline $\mathrm{H}_{2} \mathrm{O}(\mathrm{wt} \%)$ & 6.0 & & & & \\
\hline $\mathrm{CO}_{2}(\mathrm{w} \%)$ & No data & & & & \\
\hline Velocity (m/s) & 3050 & & 2980 & 4700 & 3715 \\
\hline Porosity $(\%)$ & 13 & & 25 & 8.3 & 16.1 \\
\hline Saturation $(\%)$ & 100 & & & & \\
\hline Grain density $\left(\mathrm{Mg} / \mathrm{m}^{3}\right)$ & 2.5 & & & & \\
\hline Density $\left(\mathrm{Mg} / \mathrm{m}^{3}\right)$ & 2.3 & 2.01 & 2.10 & 2.27 & 2.34 \\
\hline
\end{tabular}

\subsection{Stemming and Emplacement}

Stemming in the emplacement hole consisted of alternating pea gravel and fines materials with a single, 15.2-m cement plug at the surface. Pea gravel and 1-in.-diam steel balls were emplaced near the working point. One-inch diameter steel balls were poured into the emplacement pipe from 1100-1402 m, and the rest of the pipe was filled with Overton sand and capped with a cement plug from the surface to $15.2 \mathrm{~m}$. No problems were noted during stemming operations. Figures $6 a$ and $6 \mathrm{~b}$ show a stemming schematic with lithology and stratigraphy.

\subsection{Downhole Diagnostics}

One hundred twenty-seven cables were emplaced from the working point to various instrument trailers at the ground surface. Cavity gas was sampled through tubing located in the emplacement pipe. Post-test gas sampling efforts were unsuccessful; no gas samples were recovered. No other downhole instruments were emplaced.

\subsection{Surface Experiments}

Several experiments on the surface were associated with the BENHAM test. A shock mitigation experiment was fielded by Sandia to develop better methods for shock-mounting diagnostic trailers on the surface. Los Alamos National Laboratory (LANL) conducted an air sampling 
experiment. Both of these were development tests, and no material useful to this review was discovered. Seismic ground motion from BENHAM was recorded by two arrays-the Sandia seismic network was active for determining the seismic yield of the test and produced records of motions from BENHAM, and the U.S. Geological Survey (USGS) fielded a crustal-faulting experiment around $U-20 \mathrm{c}$ (see Section 3.11 .1 for details).

\subsection{Predicted Phenomenology}

Empirical calculations were made before the test to predict phenomenological responses, such as cavity radius and collapse time, and identified the BOXCAR test of April 26, 1968 (eight months earlier than BENHAM) as the most suitable comparison for ground motion (Environmental Research Corporation, 1968). A venting scenario was calculated that indicated that no dynamic venting would occur. These reports are classified. Collapse to the surface was predicted, and would be predicted today using standard scaling for the NTS.

\subsection{Photos}

Pre- and post-test areal photographs were taken of the area surrounding BENHAM. Post-test photos show a pattern of east-west cracking north of the drill hole. A comparison of pre- and post-test areal photos shows rock falls caused by the explosion occurring in the canyon to the south. Since collapse to the surface did not occur, no crater is visible at the surface.

\subsection{Post-Test Drilling}

Two post-test holes were associated with BENHAM: the main hole and a sidetracked hole. Drilling of these holes was delayed while predicted collapse was anticipated. Drilling commenced January 3, 1969. As was typical on uncollapsed tests, geophones were closely monitored throughout drilling as a safety measure. The hole started producing water between 880.3 and $917.8 \mathrm{~m}$, deeper than the static water level. The hole was shut in and drilling mud was used from 1334.1 to $1629.5 \mathrm{~m}$. The average measured cavity radius was $99 \mathrm{~m}$. Ninety-six post-test samples were collected near the cavity region. These were analyzed to help determine device performance; these data are classified.

\subsection{Phenomenology}

\subsubsection{Ground Motion}

Post-test surface effects were located at or subparallel to known faults (West Boxcar and Boxcar Faults) and formed lineations along previously unknown structures (Figure 7). It is interesting to note that cracks near U-20c formed in an east-west pattern. No explanation for this has been identified.

Ground motion from BENHAM was distinctly felt in Beatty, Las Vegas, and Warm Springs. Ground-motion stations showed anomalous seismic signals in one direction. An evaluation of the data indicated the seismic wave form was coherent, and no satisfactory explanation could be determined. The boundary of the Silent Canyon and Timber Mountain calderas is to the south of U-20c at an unknown location; this boundary may have affected ground motion in the region. 


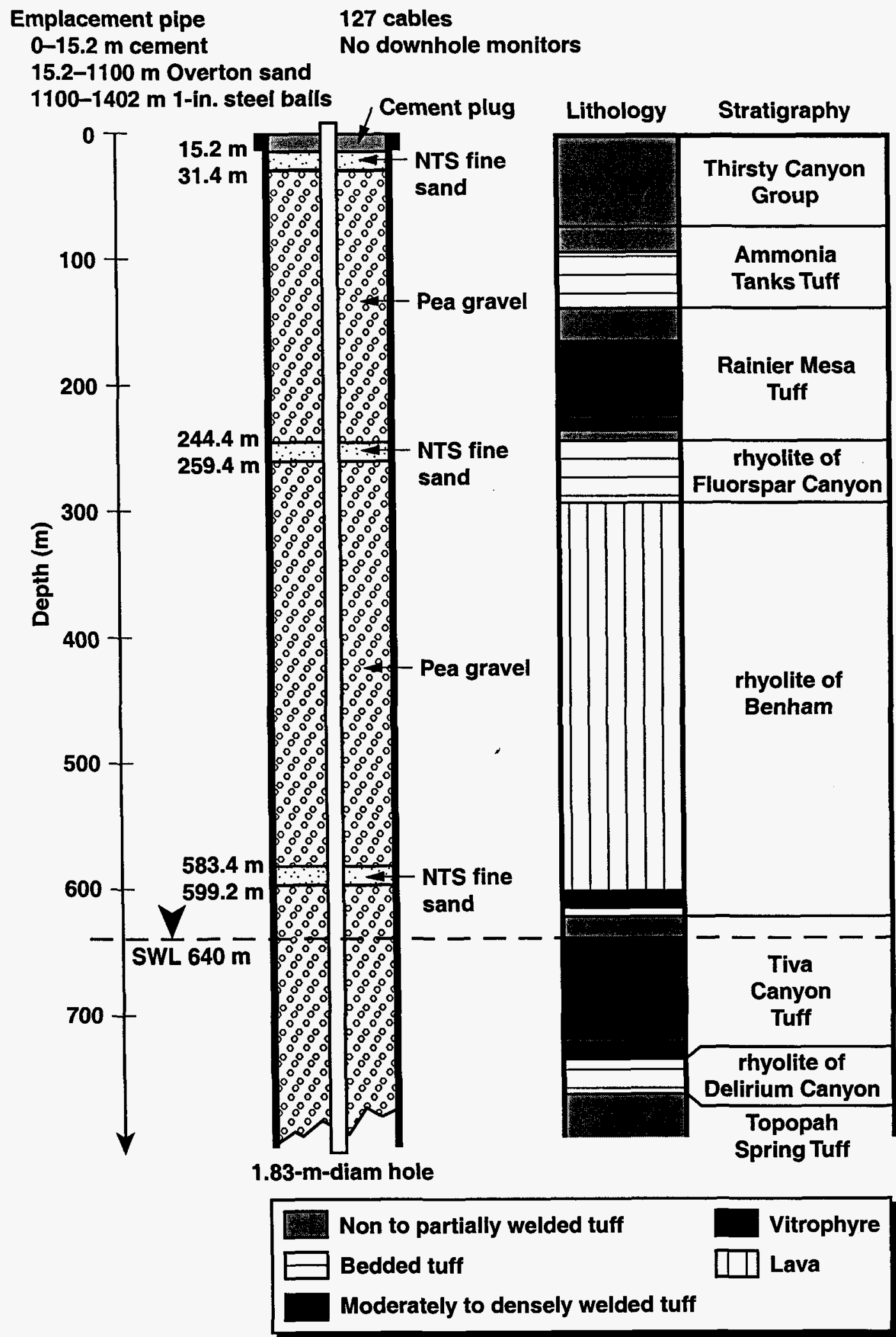

Figure 6a. Stemming schematic for BENHAM in U-20c. 

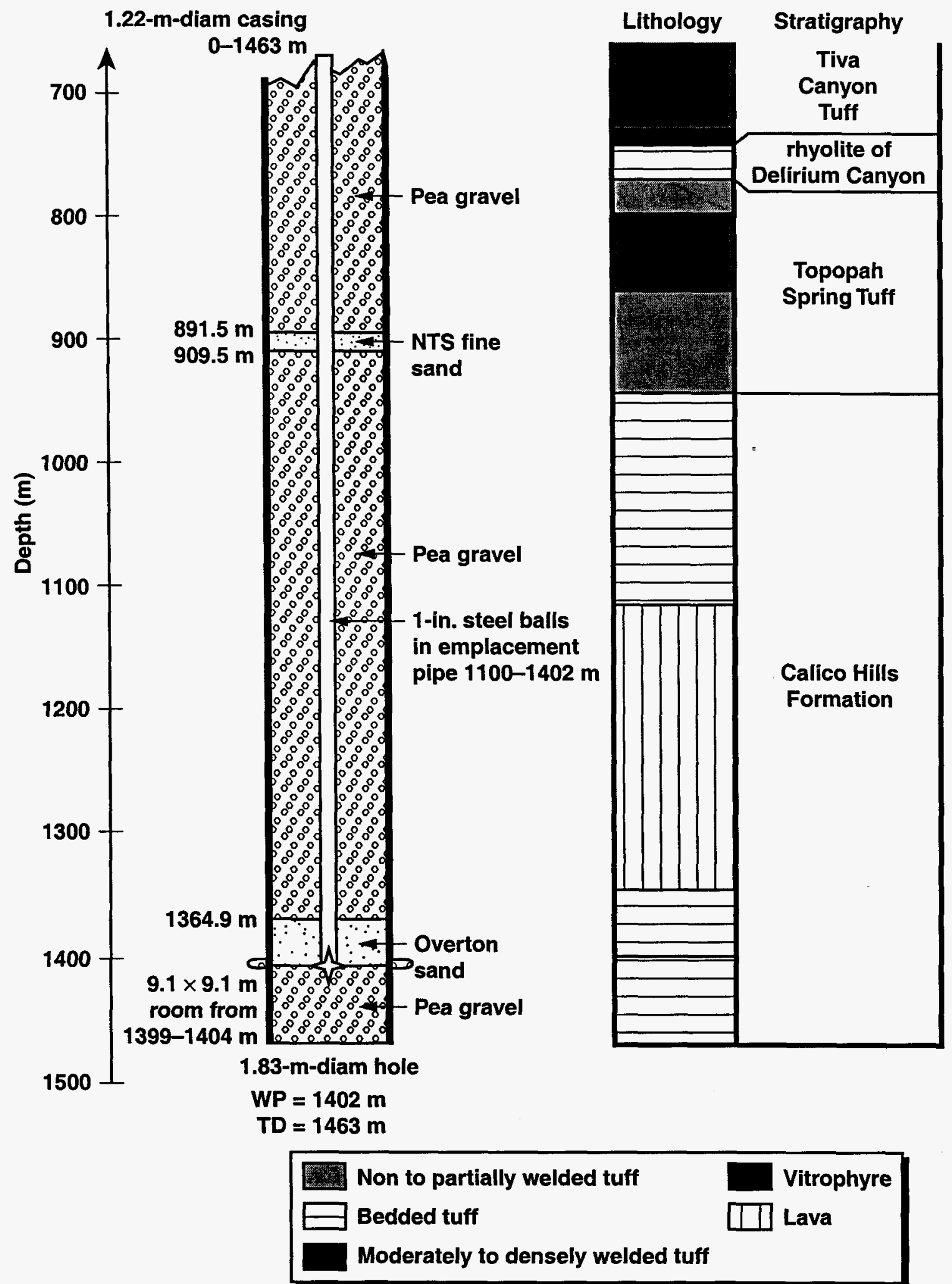

Figure 6b. Stemming schematic for BENHAM in U-20c. 


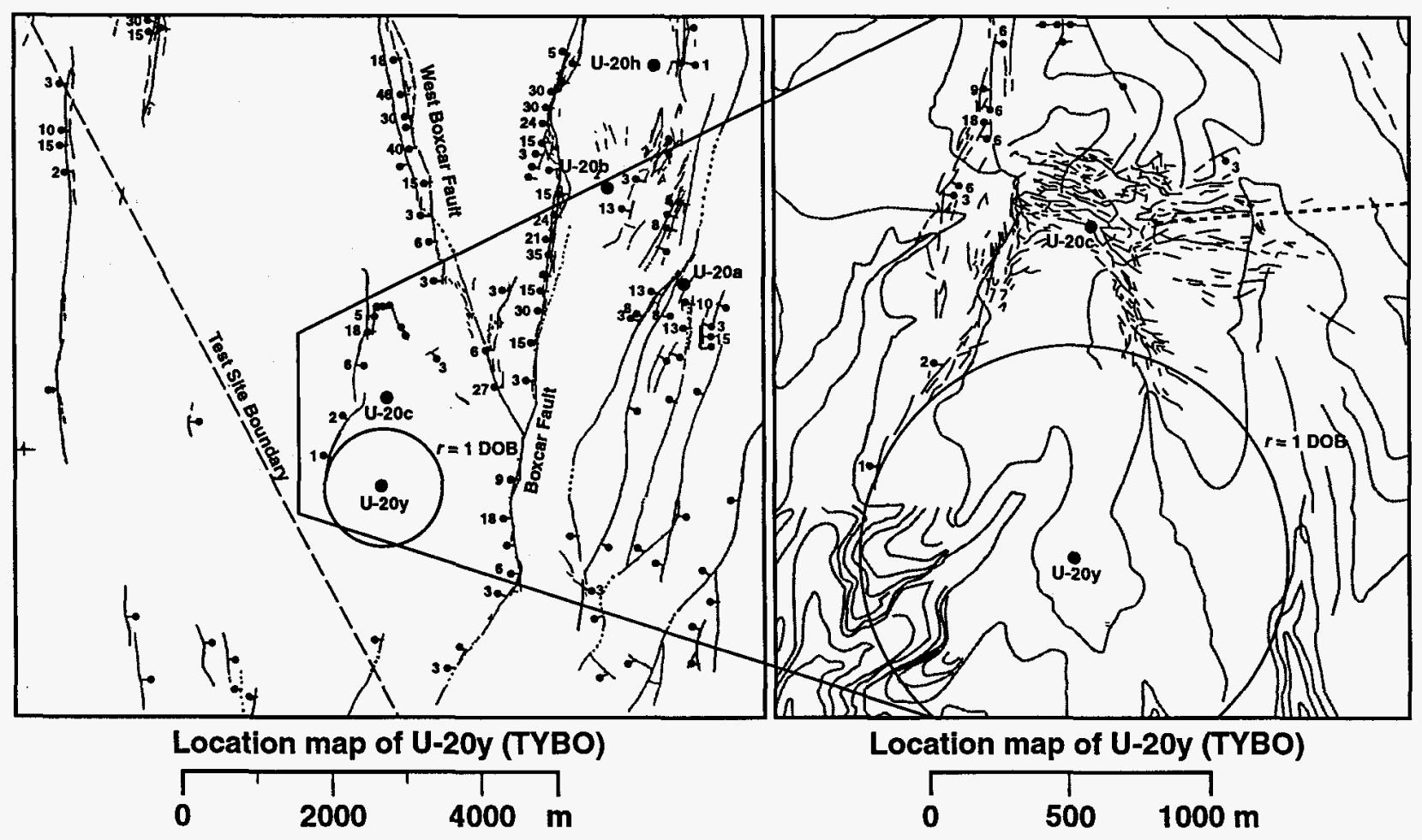

Figure 7. Surface effects from BENHAM.

The USGS experiment was the first time that an underground nuclear test was monitored by a dense network of seismograph stations capable of locating aftershocks with high accuracy and defining the P-wave first-motion pattern in sufficient detail to determine the earthquake mechanism. To summarize a paper that appeared in Science (Hamilton et al., 1969): twentyseven stations were fielded within $32 \mathrm{~km}$ of site ground zero. On day one, greater than 1000 events with a magnitude $>1.3$ were recorded; day 15 saw 15 events of this magnitude; day 24 had 140 events, and day 40 had five events of magnitude 1.3 or greater. Analysis of the data indicated two types of events were recorded-one set with a sharp beginning and a variation in radiation pattern with azimuth, and a second set of events with an indistinct beginning that increased in amplitude. Earthquakes in the first week were within $7 \mathrm{~km}$, and most events in the vicinity of the cavity occurred within this time. Activity west-southwest of ground zero showed a clear southward migration. During the third week, several large (magnitude $>4.0$ ) earthquakes occurred in this zone, and the rate of aftershocks increased dramatically along a 3 to $4 \mathrm{~km}$ southward extension of the north-south lineation. Analysis of the P-wave motion data indicates strike-slip and dip-slip motions. Conclusions from the study showed that seismic activity and fault movement resulted primarily from the release of natural tectonic strain initiated by the explosion. BENHAM caused movement on previously existing geologic boundaries (faults) and within the volcanic rocks. Surface movement occurred mainly along faults east of ground zero and was not associated with significant seismic activity. Earthquakes west of faults occurred at depth, which could correlate with a Basin and Range structure and/or the edge of the Silent Canyon caldera.

\subsubsection{Collapse}

Collapse to the surface was predicted, but did not occur. Collapse for BENHAM at this site would be predicted today using standard scaling for the NTS. 
Subsurface collapse height, or the height of the chimney from the working point, is unknown because no measurements of cables were made after the detonation or to date. Evaluation of lithologic data in the hole shows several layers, two welded ash-flow tuffs (Tiva Canyon and Topopah tuffs) and a lava (rhyolite of Benham), that could impact collapse progression. These high-density and -velocity rocks can be considered strong and could impede upward collapse. Densely welded tuffs are present at 5.8 and 7.3 cavity radii from the working point, and a lava is present at 9.6 cavity radii (to midpoint locations). "Typical" subsurface collapse on Pahute Mesa ranges between 5 and 9 cavity radii from the working point, and very much depends on the rock types. The tuffs are not very thick and are closer to the working point, making them less likely to be collapse termination points. The thick, dense lava with a base at 7.8 cavity radii extends to 11.2 cavity radii from the working point, and is a realistic candidate for terminating collapse to the surface. Because rocks overlying the lava are not as strong or pervasive, it seems likely that collapse would proceed to the surface if it continued through the lava. The distance to the lava is consistent with an evaluation of cable termination data for tests on Pahute Mesa, which suggests subsurface collapse ranges between 5.5 and 7.5 cavity radii (Olsen, 1993). A calculated chimney height of $1091 \mathrm{~m}$ places the top of the chimney near the top of the lava at $311 \mathrm{~m}$ depth (Borg, 1973). It seems reasonable that collapse terminated near or within this lava. No radioactivity above background was measured at the surface.

\subsection{Recent Calculations}

No shock-wave calculations were made before the test. John Rambo, a retired containment scientist and hydrodynamic modeler at LLNL, recently reviewed BENHAM medium-property data and analyzed their effects on cavity growth. His review, plus updated lithologic descriptions for U-20c samples, indicate that the medium properties were not homogeneous for $122 \mathrm{~m}$ above the working point as the experimenters requested, and this affected cavity growth. The zeolitized bedded tuff at the working point extends only $68 \mathrm{~m}$ above the working point. A 224-m-thick lava overlies the bedded tuff, and is itself overlain by $173 \mathrm{~m}$ of zeolitic bedded tuff. The conceptual model these layers present is a working point in a weaker rock, overlain by a strong lava, overlain by a weaker rock. Rambo calculated water content, porosity, and grain density at selected depths using density and velocity data and assuming $100 \%$ saturation. His results are shown in Table 2 and differ from what was known about BENHAM medium properties at detonation time.

Table 2. Recalculated averaged medium properties at selected intervals.

\begin{tabular}{l|c|c|c|l}
\hline $\begin{array}{l}\text { Lithology } \\
\text { (Prothro and } \\
\text { Warren, 1999) }\end{array}$ & $\begin{array}{c}\text { No. of } \\
\text { samples }\end{array}$ & $\begin{array}{c}\mathrm{H}_{2} \mathrm{O} \\
(\mathbf{w t} \%)\end{array}$ & $\begin{array}{c}\text { Porosity } \\
(\%)\end{array}$ & \multicolumn{1}{c}{ Comments } \\
\hline $\begin{array}{l}\text { Bedded tuff } \\
(937-1110 \mathrm{~m})\end{array}$ & 9 & $16.9 \pm 7.2$ & $32.7 \pm 1.2$ & $\begin{array}{l}\text { Higher porosity and water than lava, } \\
\text { weaker rock }\end{array}$ \\
\hline $\begin{array}{l}\text { Rhyolite lava } \\
(1110-1334 \mathrm{~m})\end{array}$ & 4 & $3.5 \pm 2.4$ & $7.6 \pm 4.5$ & $\begin{array}{l}\text { Low porosity and low water, strong } \\
\text { rock }\end{array}$ \\
\hline $\begin{array}{l}\text { Bedded tuff } \\
\text { (1334-1463 } \mathrm{m} \\
\text { total depth) }\end{array}$ & 6 & $12.7 \pm 2.6$ & $26.3 \pm 4.8$ & $\begin{array}{l}\text { Higher porosity and water than lava, } \\
\text { weaker rock }\end{array}$ \\
\hline
\end{tabular}


Rambo's recalculations show that cavity growth probably impacted both the bedded tuff at the working point and the rhyolite lava overlying it. His scenario suggests that:

- Cavity growth in the upward direction was very restricted due to the high strength lava of the Calico Hills Formation.

- The average strength below the cavity is calculated at 866 bars, which is strong but not as strong as the lava above the working point.

- On the basis of the measured cavity radius and medium properties, the cavity was slightly smaller than expected. Cavity pressure could have been high as high as $500-700$ bars. (Normal cavity pressure for this type of setting would have been about $300-400$ bars.)

- The lava was sandwiched between two weaker layers, and because of this, residual stress was probably narrower than normal around the cavity region owing to the hard overlying lava; cracking into the lava resulting from tensile failure might have proceeded higher in the hole than normal and may be fairly extensive. Cracks in the lava may not have been closed by the narrower-than-normal residual stress. It is possible that high cavity pressure drove steam or water upward until the time that pressure was reduced by steam condensation or collapse.

Rambo's scenario would permit radionuclides to be transported outside the cavity region into the cracked lava and emplaced upward in the saturated zone. If collapse extended to the welded Tiva Canyon and Topopah Spring tuffs-as it most likely did-the combination of high cavity pressure and tensilely failed lava could have permitted noncondensed radionuclide gas to rise to the welded tuff aquifer. Brikowski (1991) describes enhanced contaminant transport if upward flow exists in a drill hole. Since hydrologic tests were canceled in UE-20c, it is not known if upward flow exists at this location. Downward flow was identified at ER-20-5 \#1 (1 liter per minute or less at 710.2, 743.7, and $777.2 \mathrm{~m}$ ), and flow measurements were inconclusive at ER-20-5 \#3 (US DOE, 1997). Groundwater modelers should investigate the possibility of radionuclides at the tuff aquifer and transport down gradient from U-20c via the enhanced flow that Brikowski describes. 


\subsection{Evaluation of Site-Specific Information for TYBO}

\subsection{Background}

Hole construction, experiment emplacement, and post-test data were examined to determine whether modification to the in situ media by the TYBO test could be recognized. Data sources were mainly informal, including reports, memorandums, photos, laboratory data, hydrodynamic calculations, and discussions with personnel who were involved in fielding the experiments; some of these resources are classified.

The TYBO test was executed on May 14, 1975 at a depth of $765 \mathrm{~m}$ in drill hole U-20y on Pahute Mesa. TYBO was part of a high-yield testing program at Pahute Mesa during the 1970s and has an official yield of 200-1000 kt (US DOE, 1994).

\subsection{Hole Construction}

Drilling was started on U-20y, a 2.44-m-diam hole, on June 5, 1971, and a total depth of $586.74 \mathrm{~m}$ was reached August 31, 1971. The upper portion of the hole (surface to $339.9 \mathrm{~m}$ ) was drilled with vacuum circulation; reverse circulation with air and water was utilized from $339.9 \mathrm{~m}$ to $586.74 \mathrm{~m}$.

A static water level of $640 \mathrm{~m}$ was predicted before drilling commenced. However, at a depth of $586.74 \mathrm{~m}$, elevated water levels were measured. The USGS measured water levels at $558.4 \mathrm{~m}$ on October 1971; $563.0 \mathrm{~m}$ on June 1972 ; and $563.2 \mathrm{~m}$ on July 1972 ; note the slowly decreasing water level. It was thought that the zeolitized tuff in the lower portions of the hole was acting as a cistern for perched water, which was either naturally occurring water or drilling fluids returning to the hole, or the water level had been hydraulically mounded by the BENHAM test $1175 \mathrm{~m}$ north-northeast of TYBO (Dudley, 1972).

U-20y was recompleted to its final depth of $793.10 \mathrm{~m}$ using reverse circulation with air and water. Recompletion drilling started November 8, 1974, after removing approximately $1.2 \mathrm{~m}$ of fill. A 1.83-m-diam liner was emplaced from 551.7 to $787.6 \mathrm{~m}$ to ensure a dry working point for the test. Although several attempts to retrieve equipment dropped in the hole while drilling were necessary during both drilling periods, no unusual problems were encountered.

The static water level stabilized at $630 \mathrm{~m}$ after recompletion of the drill hole. There are several plausible explanations for the original high water level during the first drilling:

- Perched water at this location. U-20bb expressed a similar "perched" water level that receded to the predicted regional water level when the hole was deepened to a more permeable lava (Newmark and Wagoner, 1990). Terminating the drill hole in a less permeable unit near the static water level may permit water to appear perched. Deepening the hole to a more permeable layer permitted the water to "drain" to the more permeable unit.

- An error of $10 \mathrm{~m}$ in predicting the water level using sparse data is also reasonable.

- A 10-m modification to the static water level via groundwater mounding is possible (Knox et al., 1965; Burkhard and Rambo, 1991; McKague et al., 1991). The larger yield of BENHAM could cause such an effect.

Bottom-hole temperature was measured at $92^{\circ} \mathrm{F}$. This temperature increased to $104^{\circ} \mathrm{F}$ after the liner was installed. 
Cutting samples were collected over the total depth of the drill hole. Geophysical logs were run in U-20y. Geologic and geophysical data from the hole appear typical for the formations penetrated. Geologic structure is simple, as shown in Figure 4.

Drilling rates have been used to indicate relative strength of the lithologic units penetrated. This information is summarized in Figure 8. As expected, lower rates correlate to the stronger lavas and welded tuffs, whereas higher rates correlate to bedded and nonwelded tuffs.

\subsection{Nearby Features}

\subsubsection{Nearby Holes}

Nearby holes include the 18-m-deep U-20x, which is an abandoned emplacement hole $32 \mathrm{~m}$ from the SGZ of U-20y. This hole was filled with dirt and abandoned when hole requirements for a planned test changed. Holes U-20c, UE-20c, and U-20c I1 are located about $1150 \mathrm{~m}$ north of U-20y and were used on the BENHAM test. Instrument holes U-20y I1 (36.6-m total depth), I2 (53.6-m total depth), and I3 (36.6-m total depth) were instrumented and grouted for groundmotion studies associated with TYBO.

\subsubsection{Nearby Surface Effects}

Nearby surface effects include surface expression of structural features and test-induced fractures from the BENHAM test (Figure 7). A fault with 0.01-m displacement occurs $770 \mathrm{~m}$ northwest of U-20y; its closest approach to the TYBO working point was $500 \mathrm{~m}$. An associated zone of fracturing from BENHAM extends southeast from U-20c to within $660 \mathrm{~m}$ of U-20y.

\subsection{Working-Point Medium Properties}

The working point for TYBO was at $765 \mathrm{~m}$ in the moderately welded Topopah Spring Tuff. Partially welded and bedded tuff occurs above this unit, and densely welded ash flow tuff occurs below it. Averaged medium properties were derived from cuttings and logs obtained in $\mathrm{U}-20 \mathrm{y}$, and measurements on core data taken from UE-20c and then projected to similar lithologic units in U-20y. These data are summarized in Table 3. Averaged medium properties for stratigraphic zones in U-20y compare well to data from UE-20c, UE-20d, and UE-20f (McKague, 1975), indicating that material properties should be similar for these stratigraphic zones in this area on Pahute Mesa.

Table 3. Averaged medium properties for selected zones at TYBO.

\begin{tabular}{l|c|c|c}
\hline Property & $\begin{array}{c}\text { Working point } \\
(765 \mathrm{~m})\end{array}$ & Overburden & $\begin{array}{c}\text { Bedded tuff } \\
\text { (above working point) }\end{array}$ \\
\hline \hline Gas porosity (\%) & 0 & & 9 \\
\hline $\mathrm{H}_{2} \mathrm{O}(\%)$ & 14 & & 14 \\
\hline $\mathrm{CO}_{2}(\mathrm{dry}$ wt\%) & $<0.5$ & & \\
\hline Velocity $(\mathrm{m} / \mathrm{s})$ & 3625 & 2290 & 2840 \\
\hline Porosity $(\%)$ & 28 & & 35 \\
\hline Saturation $(\%)$ & 100 & & 75 \\
\hline Grain density $\left(\mathrm{Mg} / \mathrm{m}^{3}\right)$ & 2.6 & & 2.6 \\
\hline Density $\left(\mathrm{Mg} / \mathrm{m}^{3}\right)$ & 2.0 & 2.0 & 1.9 \\
\hline
\end{tabular}




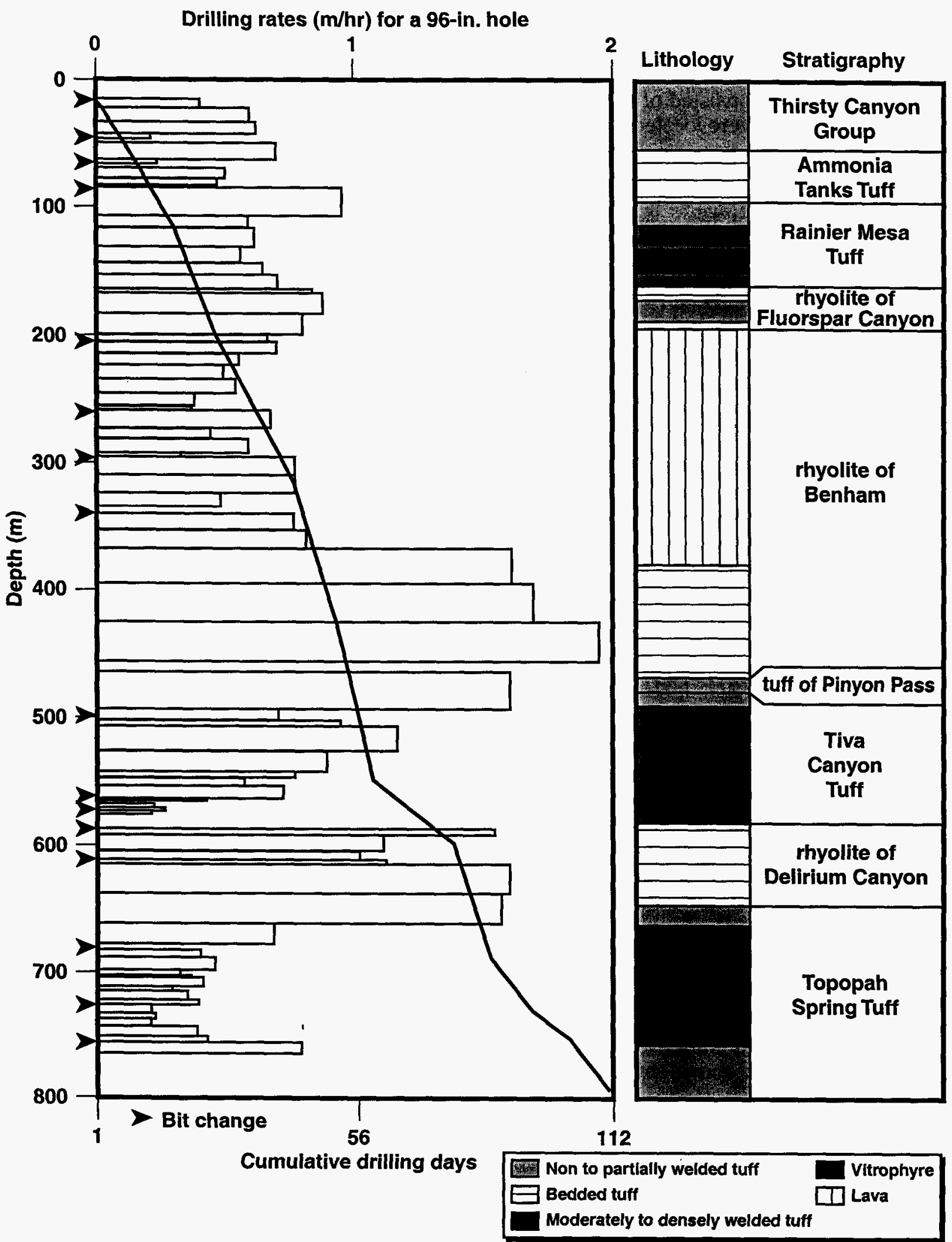

Figure 8. Drilling information for U-20y. 


\subsection{Stemming and Emplacement}

The TYBO canisters were uncomplicated and short, and the top canister ended at a depth of $752.9 \mathrm{~m}$. Stemming consisted of sand around the canisters, LLL stemming mix, and three rigidplastic plugs. Plugs were located at the top of the liner, midway up the stemming column, and in the top casing. The uppermost portion of the hole was stemmed with sand, foam cubes, a soft plug, and then LLL stemming mix to the surface. A ventilation tube was used during stemming to ensure that the air vented and a competent stemming column formed, and that no cable damage occurred due to material slumping. Figure 9 illustrates the stemming column and an updated lithologic log from Prothro and Warren (1999).

\subsection{Downhole Diagnostics}

Sixty-five cables connected the working point to various instrument trailers at the ground surface. RAMS were emplaced at 5.2 and $21.9 \mathrm{~m}$, straddling the uppermost plastic plug. No signals above background were seen on the RAMS. There was no gas sampling on TYBO. Slifer cables were emplaced to provide measurements of performance and collapse.

\subsection{Surface Experiments}

Two surface experiments were planned to investigate the high seismic ground motion predicted for this test. Sandia fielded 11 surface-motion stations, 7 in a line N18W and 2 each spanning faults-an unnamed fault about $770 \mathrm{~m}$ west of SGZ, identified by surface effects from BENHAM, and the Boxcar Fault to the east of SGZ. LLNL fielded triaxial velocity and acceleration stations in three satellite holes and three surface holes along a line N45E from SGZ. Station locations are shown in Figure 10.

\subsection{Predicted Phenomenology}

Pre-test one-dimensional calculations predicted a smaller cavity radius than average for Pahute Mesa tests, since much of the cavity was in what was considered strong Topopah Spring Tuff. The shock wave was expected to be complex due to impedance mismatches caused by layering, but not problematic. No openings between layers were calculated. Peak surface motion was predicted to be high on the basis of motion from previous tests in this area. The seismic station at Kanab had recorded large amplitudes for BENHAM, and similarly large amplitudes were expected for TYBO. It was unknown if the canyons to the south and southwest would cause stress relief between $U-20 y$ and U-20c.

\subsection{Photos}

Standard pre- and post-test areal photos were taken; comparison of these photos shows rock falls in the canyons to the south and southwest. Post-test photos show the collapse crater offset from SGZ, linear cracks within the crater, and random cracks immediately to the north. A ground-motion movie shows several views of a bulging surface caused by uplift, slap down, and crater collapse.

\subsection{Post-Test Drilling}

Drilling of the only post-test hole for TYBO commenced on May 15, 1975. Drilling mud was used at $823.6 \mathrm{~m}$. Post-test samples were analyzed to help determine device performance; these data are classified. 


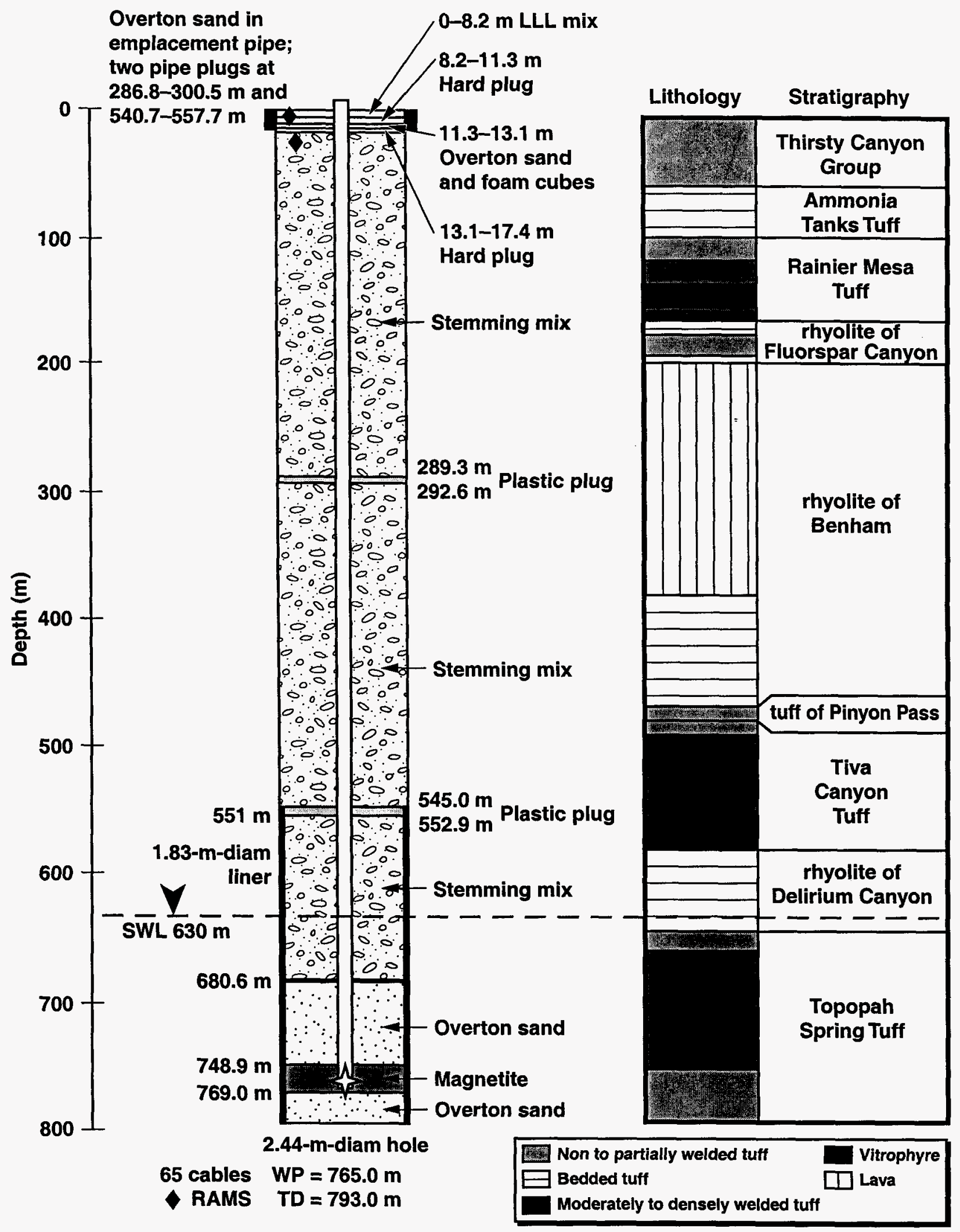

Figure 9. Stemming schematic for TYBO in U-20y. 


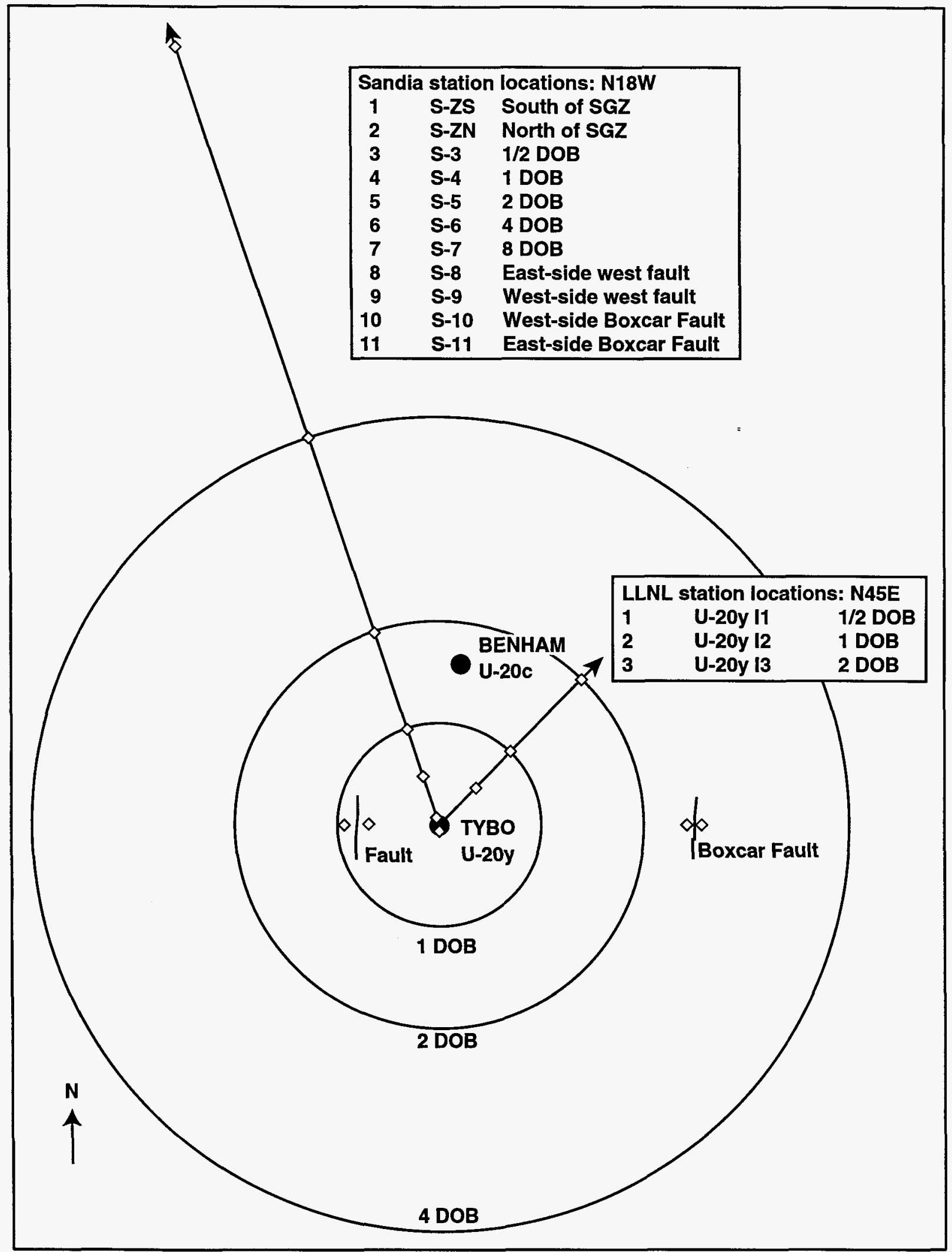

Figure 10. Surface seismic-station locations for the TYBO test. DOB is depth of burial, and SGZ is site ground zero. 


\subsection{Phenomenology}

\subsubsection{Ground Motion}

In addition to determining standard device performance, measuring ground motion was the issue at TYBO. There was physical evidence indicating that the considerable block motion of surface and near-surface materials was due to spalling effects caused by the stress wave. High peak ground motion of $9 \mathrm{~m} / \mathrm{s}$ and $6 \mathrm{~m}$ of displacement were measured, giving TYBO the highest measurements on Pahute Mesa to date. In comparison, GREELEY (official yield of $870 \mathrm{kt}$ ) exhibited a peak surface velocity of $7.6 \mathrm{~m} / \mathrm{s}$, and BOXCAR (official yield of $1.3 \mathrm{Mt}$ ) had $6.4 \mathrm{~m} / \mathrm{s}$. Accelerometers in Las Vegas indicated an unusually strong short-period verticalcomponent first arrival and peak vector values that were somewhat higher than predicted. Seismographs were reviewed to determine if ground motion was anomalous; analyses concluded that the first motion was unusually impulsive, but within the ranges noted for GREELEY and BOXCAR. Comparison of Sandia and LLNL seismic data showed little significant difference in near-field peak velocity signals along the two linear arrays, indicating similar lithologies and no discontinuities along the two arrays (Figure 11).

Test-related surface effects caused by TYBO are shown in Figure 12. TYBO reactivated cracks caused by BENHAM and caused significant cracking and local formation of pressure ridges (Howard, 1981).

\subsubsection{Collapse}

The TYBO ground-motion movie is an excellent example of the impact of the shock wave from a buried nuclear test on surrounding materials. The film shows the area immediately surrounding $\mathrm{U}-20 \mathrm{y}$ viewed from the air. No timing synchronization is available. The flash at zero time is visible, the ground-surface bulges are due to displacement caused by the outgoing shock wave, the ground-surface cracks and falls are due to slapdown, and finally a collapse crater is formed.

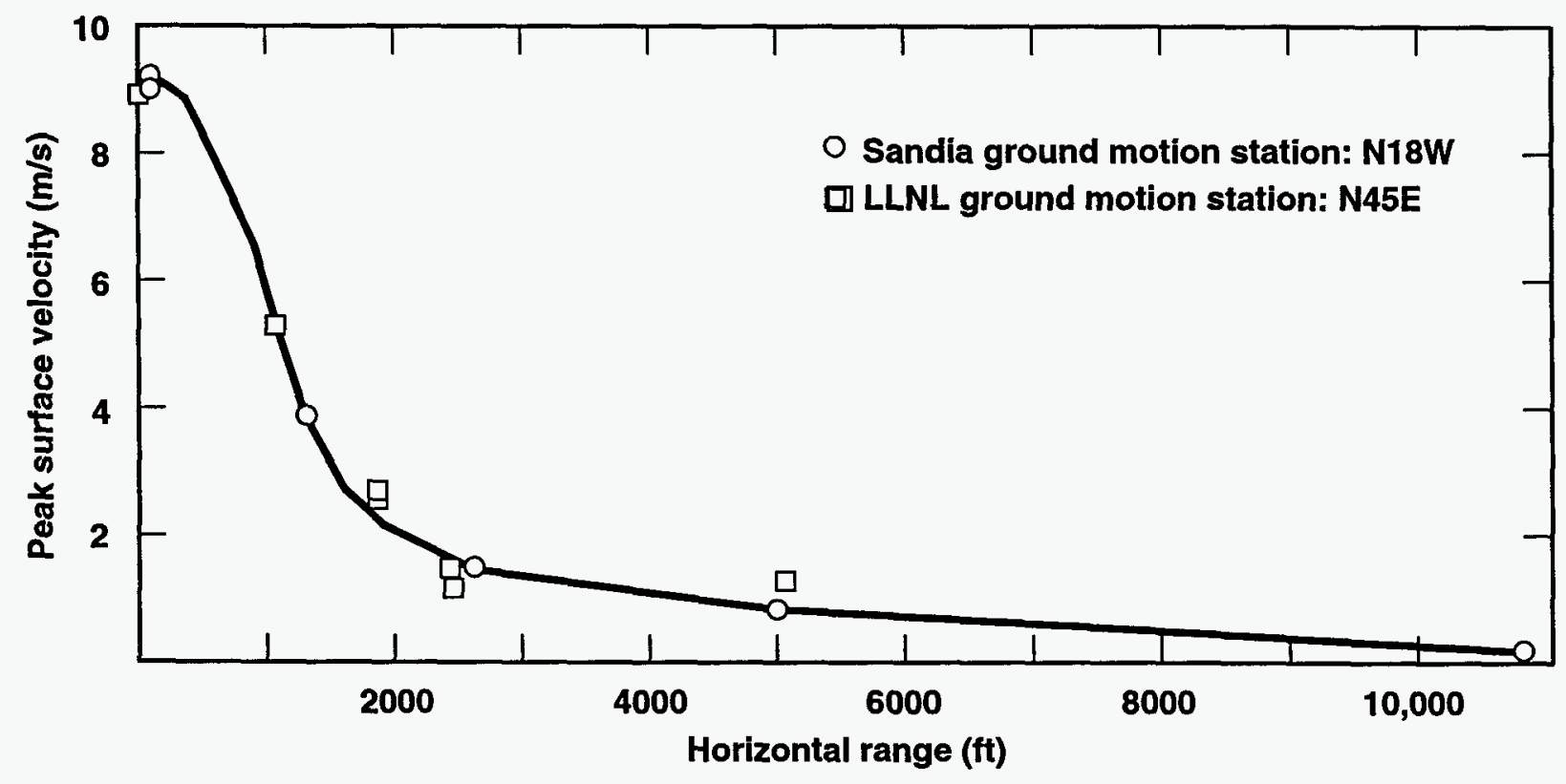

Figure 11. Peak surface velocity comparisons: Sandia and LLNL stations. 


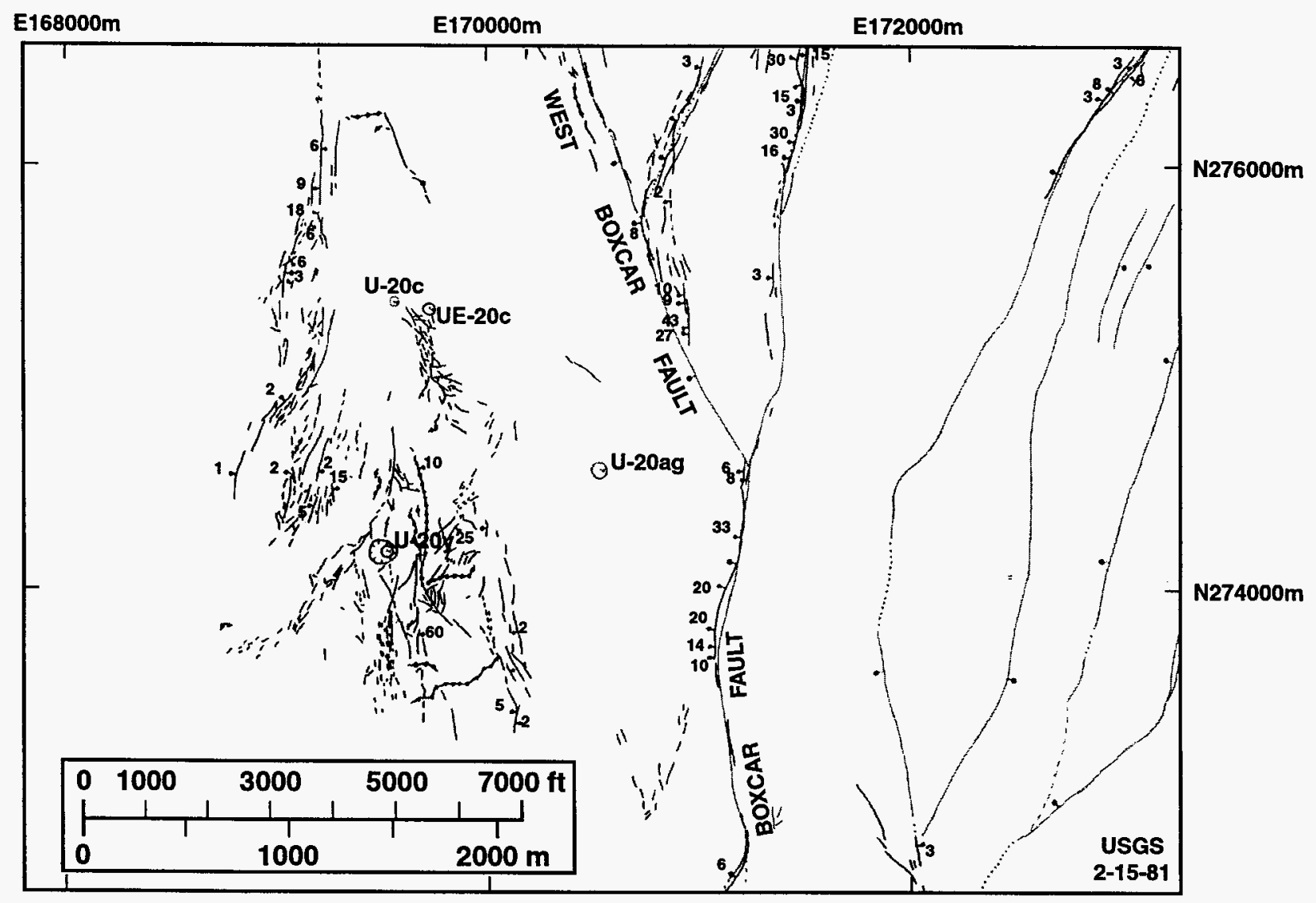

Figure 12. Surface effects from TYBO.

Ground motion from TYBO is summarized in Figure 13. Figure 13a shows uplift of the surface material and restricted linear expansion cracks southeast of SGZ. No dust is formed. Figure 13b shows the linear expansion cracks extending to the north-northeast, and the continued uplift opens them. Radial divergence causes a semirandom pattern of hairline cracks to appear on the prepared surface of the north cableway; these are not as linear as the first expansion cracks. The first appearance of surface collapse occurs from the south and may be stress relief from the canyon. The surface collapse moves clockwise to the west as blocks of rock slap down causing dust to rise from preexisting surface cracks (Figure 13c). The initial expansion cracks continue to extend linearly, more semirandom cracks are visible on the cableway, and dust extends in an arc covering the western quarter of the 1-DOB circle (Figure 13d). Two distinct north-northwest-trending lineations are formed, one extending from SGZ south and a longer lineation offset to the west (Figure 13e). The length and linearity of the features indicate that these must define a previously unknown subsurface structure. In a sweeping clockwise motion, most of the western half is covered with rising dust. The entire eastern half of the 1-DOB circle is now cracked by uplift. Breakage between the lineations forms polygons, probably defined by preexisting surface fractures/cooling joints. Still no dust is visible in the uplift region. Dust from slapdown covers almost the entire perimeter of the circle (Figure 13f). Cracks radial to SGZ start to form in the eastern interior of the circle. Dust rises from rock polygons as they slap down. The final block, offset east-southeast of SGZ, is visible as it collapses. Although the entire area is now dusty, the two northeast lineations are still present, defined by dust clouds (Figure 13g). A final crater is formed, offset to the west from SGZ. 


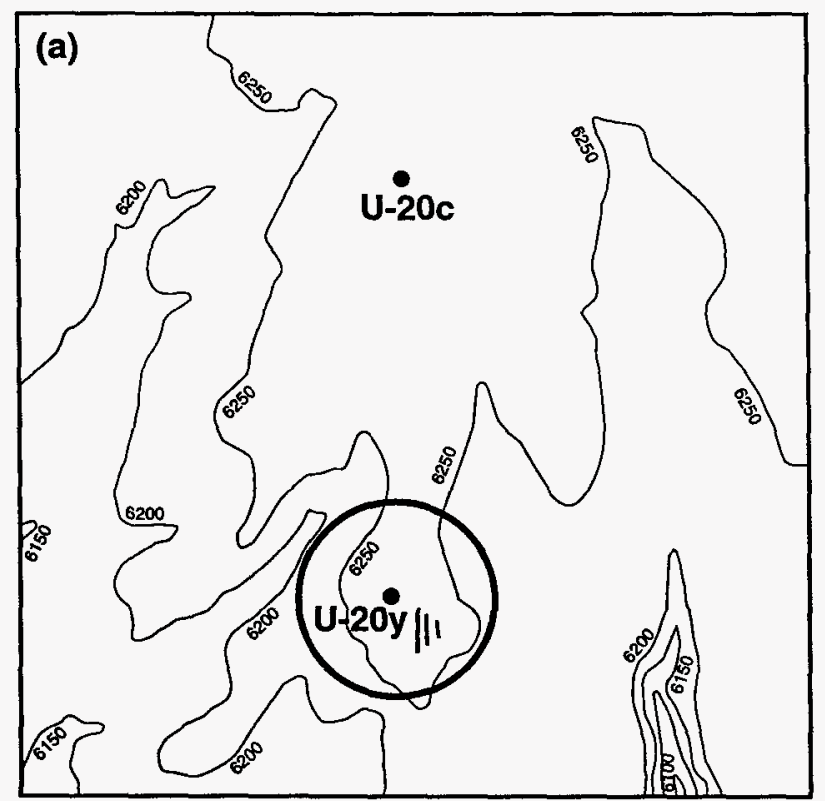

Extension cracks form from surface bulge.

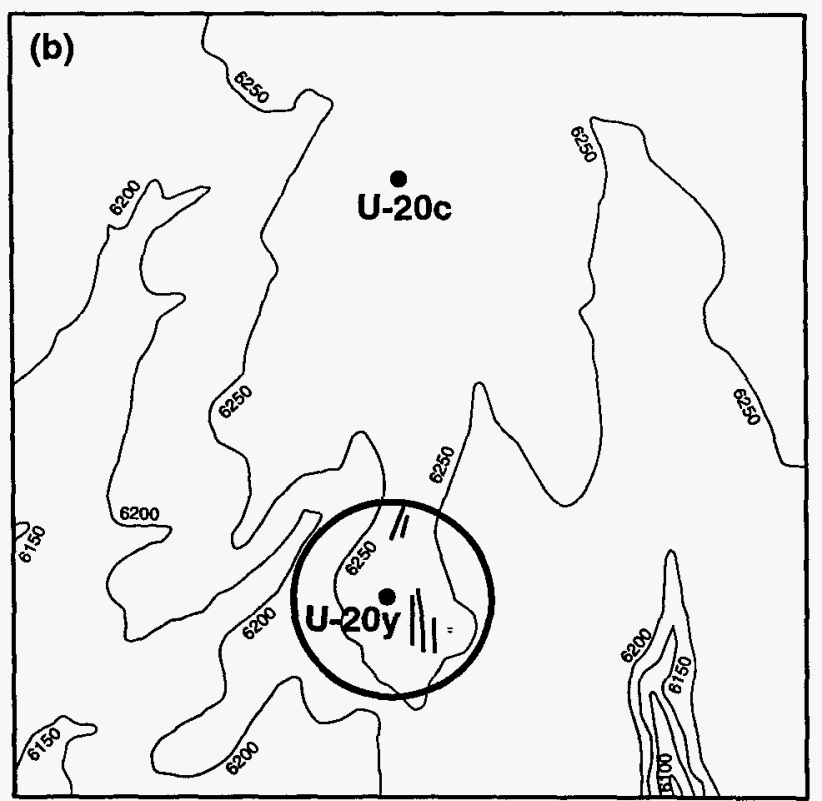

Cracks extend. Hairline cracks appear on the cableway.

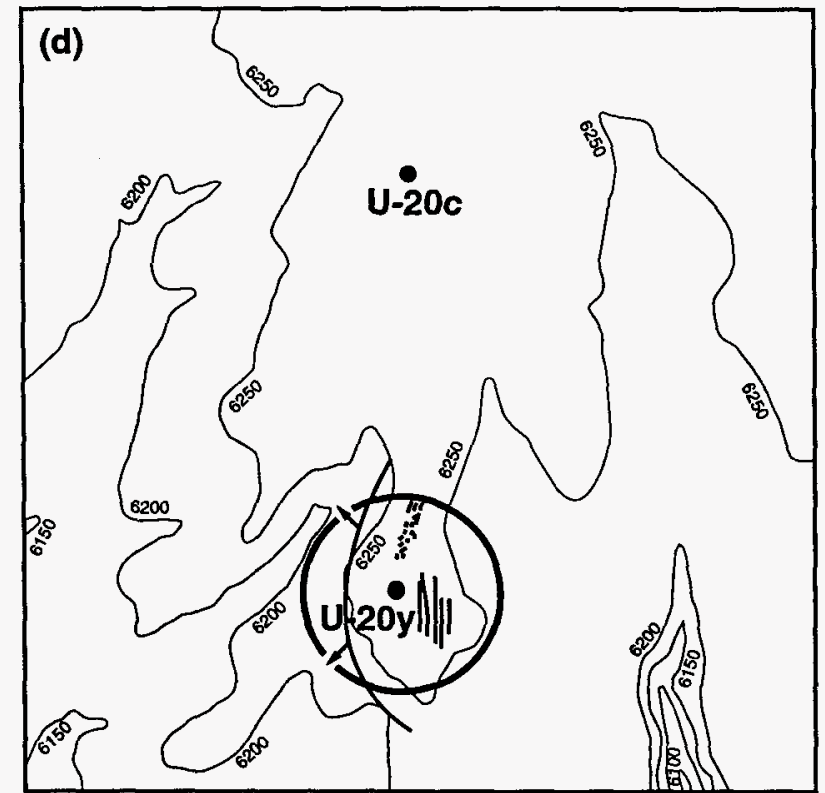

Slap down occurs on west side with visible dust. Many cracks are present on cableway. Extension cracks are enlarging.

Figure 13. Collapse evolution derived from the TYBO ground-motion movie. 


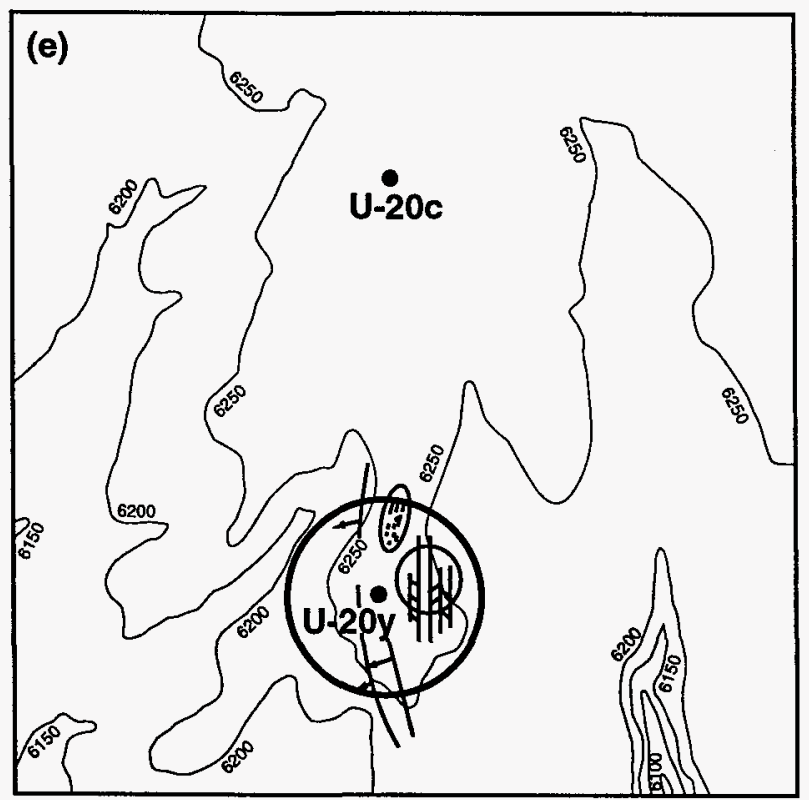

Two distinct lineations are formed by collapse. Dust covers the western half of the circle. The entire circle area is covered with cracks and merging lineations.

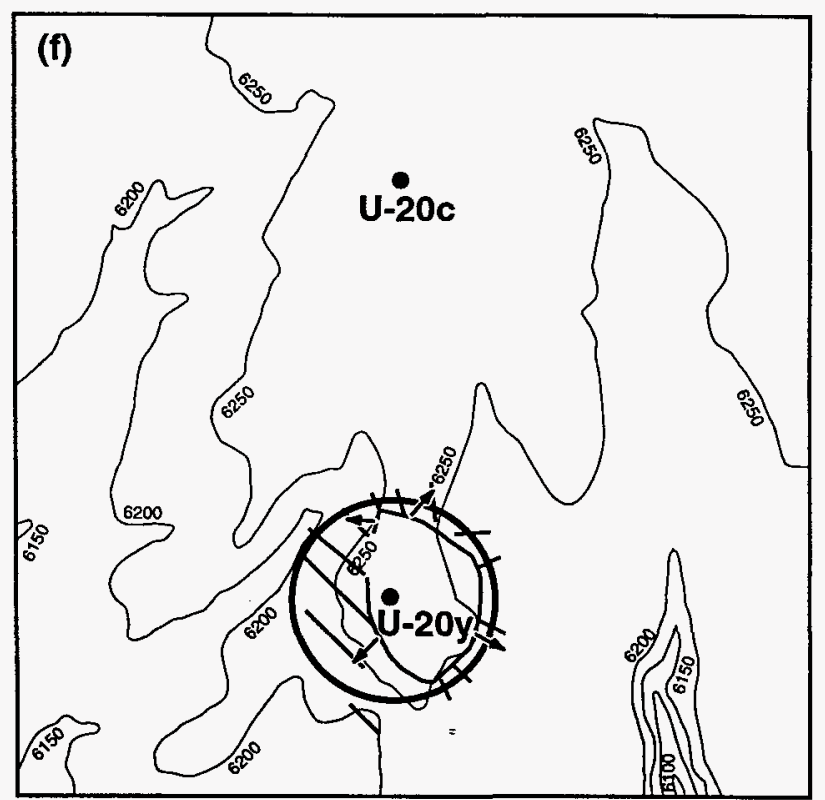

Dust from slapdown is present outside the perimeter; radial cracks form in the central portion of the circle.

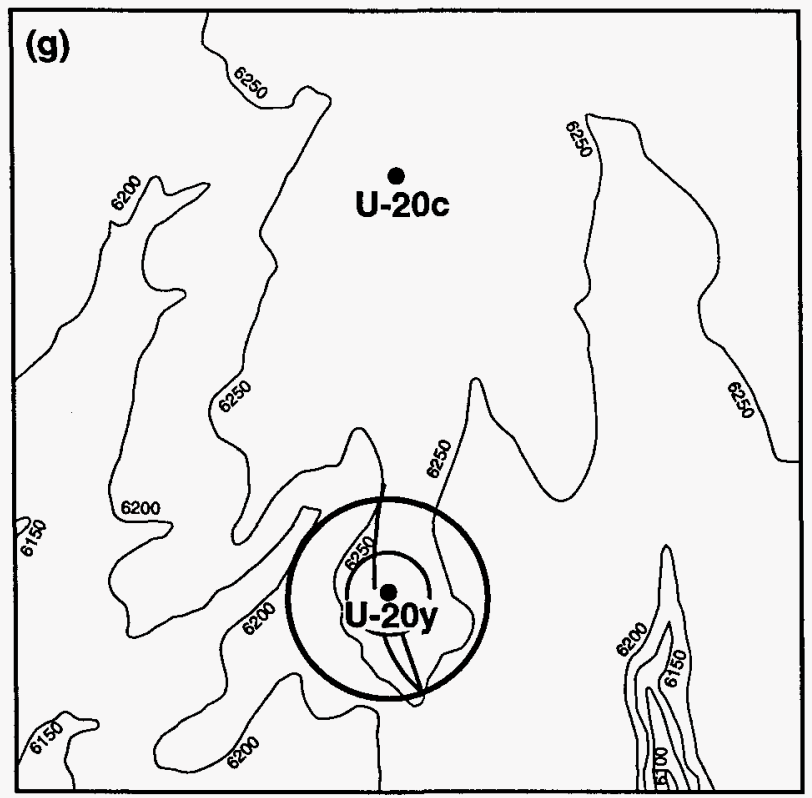

Dust rises from polygons as they slap down. Lineations are still visible. The entire area is now dusty. The final crater shape forms as the last collapse block falls.

Figure 13 (continued). Collapse evolution derived from the TYBO ground-motion movie. 
Collapse occurred $4 \mathrm{hr}$ and $12 \mathrm{~min}$ after detonation time. Re-entry crews noted severe fracturing near the crater area, and personnel entry to the crater was not permitted for safety reasons. Post-test surveys show the collapse crater to be roughly circular, composed of two zones, and offset from SGZ (Figure 14). Four diameters were measured. The maximum crater radius is $139.6 \mathrm{~m}$ to the south, and the minimum radius is $77.1 \mathrm{~m} \mathrm{S39W}$. The inner zone has a welldefined lip at an average radius of $68.3 \mathrm{~m}$; an outer zone with a poorly defined lip has an average radius of $99.0 \mathrm{~m}$. The maximum depth of the crater is $13.84 \mathrm{~m}$ to the west of SGZ. No levels of radiation above background were detected.

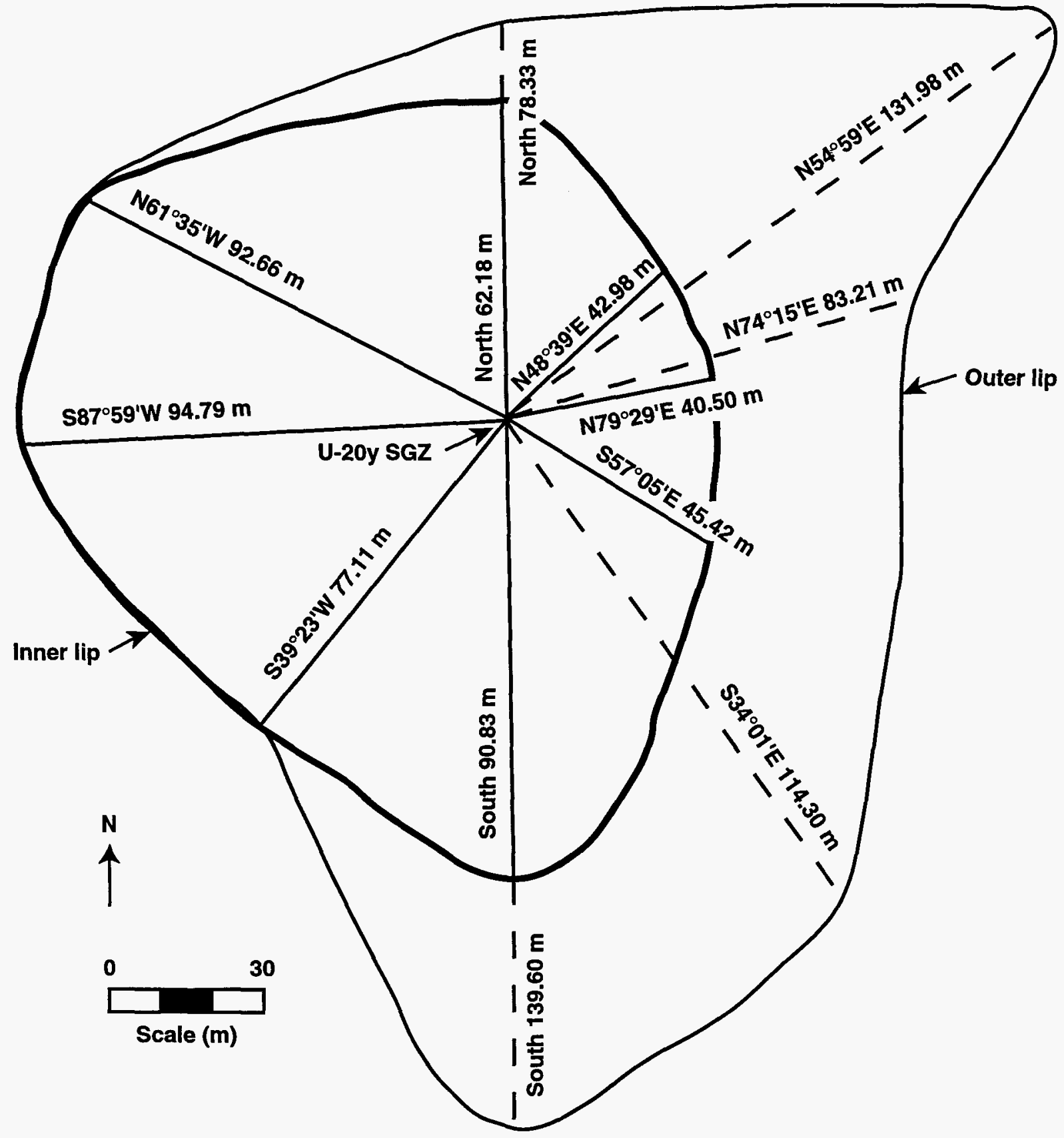

Figure 14. TYBO crater measurements. 


\subsection{Calculations After the Test}

Pre-test calculations consisted of one-dimensional analyses. Even though high ground motion was predicted, measured values were several times higher. One- and two-dimensional post-test calculations were undertaken to investigate this difference. Rambo and Bryan (1983) concluded that the refraction of the plastic portion of the surface velocity wave above the water table caused the high SGZ velocity measured. The high surface velocity was enhanced by (1) a porosity difference between the saturated unit below the water table and about $14 \%$ porosity in the unit above the water table; and (2) a scaled distance of $20-40 \mathrm{~m} / \mathrm{kt}^{1 / 3}$ from the explosion point to the water table that accentuated the focusing.

John Rambo (LLNL) recently reviewed these calculations and provided the following phenomenological explanation (personal communication, 1998).

- The elastic portion of the shock wave proceeded on a direct path to the surface away from the explosion center.

- The peak surface velocity wave had a longer path because it focused off the water table, which was located between 1 and 2 cavity radii from the working point. This focusing was strongest directly above the working point and diminished rapidly radially, as shown in Figure 11.

- The above focusing caused tensile failure below the water table due to rarefaction downward off the water surface.

- The calculated zone of tensile failure can be viewed as similar to spall or a brief opening just below the water table. The tensilely failed area below the water table extended to a radius of $200 \mathrm{~m}$.

Rambo's scenario indicates a zone of failure immediately above the cavity region to the top of the water table. The zone extended about $200-\mathrm{m}$ radius away from the drill hole. Note that this is larger than the largest crater radius measured. Radionuclides could travel upward in this failed zone to the top of the water table. 


\subsection{Evaluation of Generalized Containment Data for Phenomenological Models}

As part of the engineering and containment process, the physical environment is characterized to some extent before a nuclear test to predict how the explosion will interact with the rock media. Evaluating the physical environment surrounding an expended site is critical to accurately model radionuclide transport in the groundwater away from the detonation point. It is important to understand how the media were altered and where the radionuclides are deposited.

To review, we know that:

- The nuclear explosion vaporizes, melts, crushes, and cracks the surrounding rock medium.

- Cavity expansion causes radial cracking.

- Residual stress usually closes fractures that were opened during cavity expansion.

- Areas of damage may exist beyond two cavity radii if residual stress is insufficient.

- Locations exist from which radionuclides can escape from the cavity region.

- Once cavity pressure is less than lithostatic pressure, radionuclide transport is controlled by rock strength and preexisting conditions. Radionuclides can then move only via noncondensable gas transport or groundwater flow.

- Chimney zones are areas of bulking caused by collapse.

- Almost all long-lived radionuclides are contained within the puddle glass at the bottom of the cavity.

The phenomenological model identifies the cavity and shock-damaged regions and the chimney or collapse region. Shock damage is highly dependent on the material properties of the surrounding rock, and is increased when gas porosity is low, shear modulus is high, water content is high, and higher strengths are present at confining pressures (Rimer, 1981). The strength of the stress wave also controls shock damage (Martin et al., 1993).

\subsection{Regions of the Phenomenological Model}

\subsubsection{Puddle Glass Region}

Most radionuclides are contained within the puddle glass at the bottom of the cavity. Enriched in the glass are low-boiling, high-vapor-pressure radionuclides, specifically actinides. This region is known to be heterogeneous, with dense glass, froth, and rubble. The volume of rock vaporized and melted by a nuclear explosion can be estimated at $700 \mathrm{Mg}$ per kiloton of yield (Olsen, 1993). This volume should be distributed over the bottom portion of the cavity sphere or simplified as a rectangle at the bottom of the cavity region.

\subsubsection{Cavity Region}

Identification of the cavity zone is important for contaminant transport because (1) this region contains almost all of the long-lived radionuclides deposited after a test, and (2) the dynamics of cavity growth define mechanisms that can permit radionuclide deposition outside the cavity zone. Cavity size and shape are determined by the yield of the test, rock strength, cavity equation of state, and gas porosity. It is exceedingly useful to modelers when cavity size is measured via post-test drilling, even though these values are accurate to about $\pm 15 \%$ (Hudson, 1981). 
Equation (1) predicts cavity radius for tests at NTS, and is a valuable tool when cavity dimensions have not been measured or the data are classified:

$$
R_{\mathrm{c}}=\frac{70.2 \cdot(y)^{1 / 3}}{\left(\rho_{\mathrm{ob}} \cdot \mathrm{DOB}\right)^{1 / 4}},
$$

where

$R_{\mathrm{c}}$ is the cavity radius in meters.

70.2 is a constant developed for the NTS.

$y$ is the yield in kilotons.

$\rho_{\mathrm{ob}}$ is the overburden density.

$\mathrm{DOB}$ is the depth of burial in meters.

The thickness of the cavity boundary varies. Boundaries have been described as having transition zones that are: fractures with pockets of activity, solid but disrupted rock, tightly compacted powder, and fractured, where the fractures can be open or filled with molted rock. The PILE DRIVER test in granite had a transition zone of only inches, whereas at Rainier Mesa, the transition from the cavity to surrounding rock was a zone of mixed sizes and textures over 4 to $6 \mathrm{~m}$ in tuff. In the phenomenological model, the cavity radius is used to define the approximate extent of cavity growth. Because we have no new information on the thickness of cavity boundaries, the variation and inaccuracy of this boundary is incorporated in the shockdamaged zone.

\subsubsection{Shock-Damaged Region}

Shock damage is the change in the geologic medium due to the passage of an explosively driven stress wave. Identification of the shock-damaged area is important because porosity and permeability, important parameters in transport modeling, are modified in these regions. Pertinent investigations to identify damage zones on NTS rocks are summarized below; damage studies of rocks from locations other than the NTS follow.

Martin et al. (1993) observed samples of pristine and shocked NTS tuff from Rainier Mesa and concluded that:

- Shock damage caused no significant change in physical properties, specifically porosity and saturation.

- Shear-strength-stiffness moduli of shock-damaged tuff are significantly lowered for peak stresses of $200 \mathrm{MPa}$ and higher.

- The shear strength reduction was associated with measurable microstructural damage consisting of new microcracks.

- Microstructural damage as microcracks and crushed pores is present in tuffs exposed to approximate shock levels of $200 \mathrm{MPa}$ and greater. Damage increases with shock level. Below $150 \mathrm{MPa}$, damage was not conclusively observed.

- Degradation caused by shock damage (dynamic loading) is greater than that caused by quasi-static loading in the laboratory. Laboratory results were different than field results. The scale of the test is important!

- Shock-damaged tuff shows homogeneous distribution of new microcracks. 
Martin et al. (1993) also noted textural differences in tuff samples exposed to shock damage greater than $150 \mathrm{MPa}$. The textural differences consisted of low-aspect-ratio cracks and granular, poorly cemented (almost cohesionless) matrix material, which compares with cohesive, well-indurated matrix material in the pristine samples. The microcrack density was anisotropic and increased systematically with stress. The anisotropy was not fully understood; one hypothesis is that this was related to preexisting conditions in the media.

Carroll (1981) compared pre- and post-test in situ and core shear velocities of zeolitized Area 12 tuff as indicators of the range and possibly the nature of post-test effects. His goal was to develop a deterministic method to identify in situ damage since observations made during mining re-entry of the cavity and chimney zones at Rainier Mesa frequently appeared benign, and microfracturing is usually hard to distinguish visually from preexisting planes of weakness. He identified four zones of failure:

- Chimney rubble, a zone of collapsed chimney material, was present to 1 cavity radius as compacted material. This zone had no noticeable density contrast and greatly reduced velocity data compared with pre-test data.

- Pervasive microfractures ranged from 2 to 2.5 cavity radii from the working point and were generally restricted to within 2 cavity radii. Reduction in shear velocity, caused by dilation from shock-wave propagation and cavity growth, was present in both in situ and core velocities.

- Pervasive macrofractures ranged from 2 to 5 cavity radii from the working point (commonly ranged from 2 to 4 cavity radii), and usually terminated by about 3 to 4 cavity radii. Core velocities were typically unaffected, but in situ shear velocities were diminished. Whether these fractures were preexisting or new and the extent and uniformity of fracturing are unknown.

- Discrete and localized failure was visually identified within 4 cavity radii. Since these were outside the experience of pre-test shear velocity, they also were not visible in post-test velocity surveys.

Borg (1973) evaluated granite cores from Area 15 for fracture effects from nuclear tests. She concluded that macrofracture zones were present to horizontal distances of 2.7 to 3.5 cavity radii from the working point. She predicted these would increase the permeability of the surrounding rock.

Toman (1975) investigated the permeability effects of increased fracturing in gas-producing formations on the RIO BLANCO, RULISON, and GASBUGGY nuclear tests from the Plowshare Program. Permeability was increased from 1 to 3 cavity radii for RIO BLANCO and 2 cavity radii for GASBUGGY. Toman concluded that permeability was increased a lateral distance of 3 cavity radii and was highly dependent on initial reservoir characteristics.

Butkovich and Hearst (1976) performed calculations to verify field data on the damage effects of chemical explosions in coal beds. These damage effects included displacement, failure, ground motion, cavity size, crater size, and seismic effects. They found that microscopic fracturing increased permeability out to a cavity radius factor of 1.2, decreased sound speed out to a cavity radius factor of 1.7, and made drilling easier within a cavity radius factor of 2 .

\subsubsection{Collapse Chimney Region}

Collapse of the void forms a chimney above the cavity region. The height of collapse is based on explosive yield and material strength of the overlying rock. Collapse can terminate in the subsurface or proceed to the surface where a crater is formed. 
Chimney shape can be cylindrical, conical, or an inverted cone, as determined by connecting the edges of the cavity region to the maximum diameter of the surface collapse crater. Determining the shape of the cylinder sides is subjective because the surrounding lithology can greatly influence collapse propagation. More complicated methods attempt to account for variation resulting from the strength of the rock layers. Unless crater dimensions or other information dictates, we generally assume that chimney shape is a cylinder above the cavity. For contaminant transport modeling purposes, the base of the cylinder can be set equal to the cavity region diameter. Chimney height should be set to the working point depth, if collapse proceeded to the surface, or to the height of subsurface collapse. Subsurface collapse can be determined from cable measurements, estimated from scaling factors ( 5-9 cavity radii), or estimated from Eq. (2) developed by Borg (1973):

$$
H=0.88 R_{\mathrm{c}}^{1.55}
$$

where

$H$ is the calculated height of the chimney in meters.

0.88 is a constant developed for the NTS.

$R_{\mathrm{c}}$ is the measured cavity radius in meters.

Because groundwater transport of radionuclides is the focus of contaminant transport modeling, the regional water table becomes a boundary for the model. This assumption would need to be modified if perched water was present.

\subsection{Permeability}

Few measurements of permeability have been made at the NTS, and most of them are representative of large scale, in situ media. Permeability of chimneys has been measured with air-injection, tracer gas pressurization, and atmospheric pressure variations. No post-test measurements have been undertaken in the puddle glass or cavity region. Inferences can be made from re-entry photographs and descriptive records. Due to the paucity of measurements, only qualitative statements can now be made in comparing the permeability of the regions of the model.

The puddle glass region, although heterogeneous in nature, probably displays lower permeability than the "before-test" rock, because this glassy material has undergone vaporization, melting, and solidification. Photographs show solid glass areas, infallen rubble blocks, frothy glass, and baked zones. Although significant froth may exist, it is not clear if this represents connected pore space. Permeability should be considered lower than the pre-test media for this region of the model.

The cavity region above the glass puddle and the chimney are composed of collapse material. The cavity region is a heterogeneous mixture of rubblized collapse material, and melted glass near the puddle boundary and the cavity walls. The collapse chimney consists of rubble of various sizes. Collapse in the chimney causes bulking of about $15-35 \%$ for competent rocks and tuffs (Borg et al., 1976 and Boardman et al., 1964). Kunkle (personal communication, 1998) notes that movies from drilling activities into chimney zones "give the appearance that a mouse could scramble through the chimney rubble." Rambo (personal communication, 1998) expects that bulking resulting from collapse would make the edges of the chimney the most continuous and open pathway as hard rock collapses into the chimney region. Permeability measurements from chimneys in alluvium range from 7-99 darcies, similar to values measured for in-situ alluvium (Rozsa et al., 1975). Chimney permeabilities in tuffs at Rainier Mesa range from about 10-150 darcies (Peterson et al., 1977 and Peterson et al., 1978), and 1-200 darcies for Pahute Mesa rocks (Burkhard et al., 1987). Field measurements of permeability by air-injection, tracer 
gas pressurization, and atmospheric pressure variations are effected by the bulk media and probably don't distinguish the rubblized areas of the cavity region above the melt glass from the chimney region. Thus, permeability measurements of the chimney can be applied to both zones, or reduced slightly for the cavity region, based on the presence of glass.

The damaged region represents material that has been shock damaged by the outgoing shock wave. Based on observations by Borg (1973), Toman (1975) and Butkovitch and Hearst (1976), permeability of the shock damaged region should be higher than the pre-test setting. Because the material has been mechanically failed in place, it will have lower permeability than the bulked rubblized regions.

\subsection{Injection of Radionuclide Material Outside the Cavity Region}

Radionuclide material can be injected outside the cavity region by hydrofracturing (pressure driven) or spall (opening of layers during stress release). These are usually localized features. Radionuclides have been found up to 7 cavity radii from the working point in Yucca Flat (Nimz and Thompson, 1992). No documented cases of such transport have been identified on Pahute Mesa. This may be simply fortuitous, related to deep burial in fractured volcanic rocks, or wider spacing of emplacement holes on account of larger yields.

Radionuclides can be transported (pressure driven) via preferred paths, such as the stemming column or structural weakness, that are in contact with the cavity region. PIN STRIPE

(Frenchman Flat) and BANEBERRY (Yucca Flat) are well-known examples of containment failure resulting from structural weakness, i.e., faults. Future work should investigate Pahute Mesa RAMS data to evaluate the ability of the stemming column to contribute to radionuclide transport outside the cavity region. Future work should also evaluate the impact of the injection of radionuclides outside the cavity zone. This will need to be included in the phenomenological model.

\subsection{Evaluation Conclusions}

Incorporating the modified geologic media into the model is critical for contaminant transport modeling. A phenomenological model needs to identify information on the melt glass puddle, cavity, damage, and collapse chimney regions as shown in Figure 15.

- Puddle glass region: A calculated volume of $700 \mathrm{Mg}$ per kiloton of yield, distributed over the bottom of the cavity sphere. The permeability should be lower than the pre-test material because of the solidification of the melted materials.

- Cavity region: A sphere around the working point using the measured radius from post-test drilling if it is available, or a radius calculated from Eq. (1). The permeability should be greater than pre-test material, and slightly lower than that assigned to the collapse chimney region.

- Damage region: A sphere around the cavity region no less than 2 but a maximum of 3 cavity radii, refined by site-specific information. The permeability of this region should be higher than that of pre-test material because of radial fracturing from the outgoing shock wave, but lower than the collapse chimney region.

- Collapse chimney region: A cylinder with the base equal to the cavity diameter and the height equal to the collapse distance above the working point, or the height determined from scaling or Eq. (2). The permeability should be higher that that pre-test, maximized at $15 \%$ from bulking resulting from collapse. 
Site-specific information should be reviewed to refine the geometries of these regions. The presence of preexisting structures and positioning of strong and weak layers can influence cavity growth, and geologic layering can affect collapse heights. 
G. A. Pawloski

Hydro-

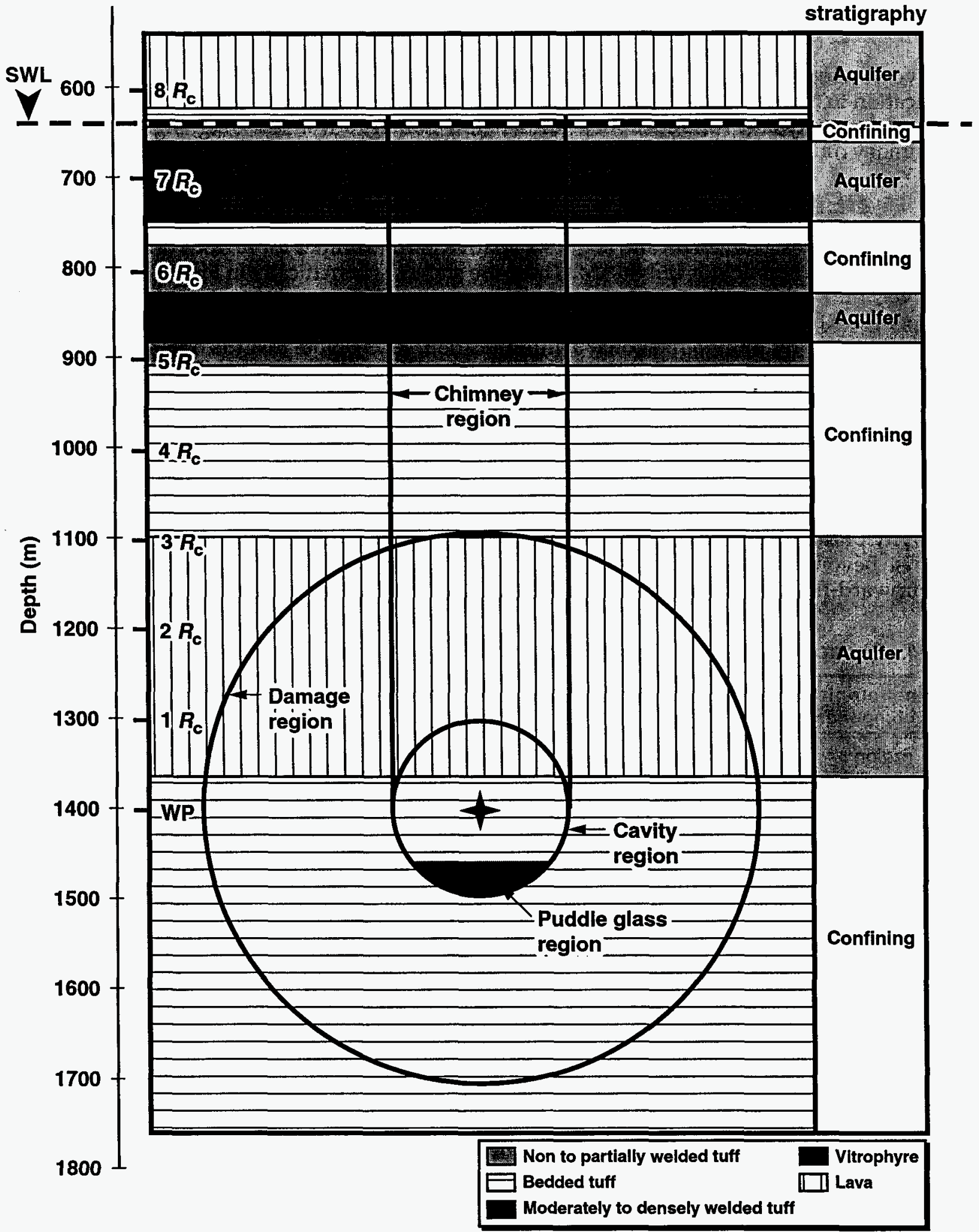

Figure 15. Schematic of a phenomenological model. 


\subsection{Phenomenological Model as Input for Groundwater Modeling}

We have developed phenomenological models for BENHAM and TYBO that account for modification to the in situ media as the result of an underground nuclear test. These include zones for the cavity and volume of rock permanently damaged from the outgoing shock wave and chimney dimensions.

\subsection{BENHAM}

Table 4 summarizes geometries and suggests relative permeabilities for regions of the phenomenological model for BENHAM. These are shown schematically in Figure 15. The cavity radius was measured at $99 \mathrm{~m}$. A damaged region is set at $297 \mathrm{~m}$, equal to 3 cavity radii. This is the upper extent recommended and matches very nicely the tensilely failed region in the rhyolite lava as suggested by Rambo (personal communication, 1998). Note that the damage zone extends through the lava aquifer. BENHAM did not collapse to the surface, and chimney height was not measured. However, the estimated height of $1091 \mathrm{~m}$ from the working point [Eq. (2)] is consistent with collapse terminating in the rhyolite of BENHAM and seems reasonable.

Saturated flow and transport simulations will set the static water level as a model boundary.

Rambo's scenario suggested possibly "lifting" radionuclides in the saturated zone. Because collapse probably extended beyond the welded Tiva and Topopah tuffs, the combination of high cavity pressure and tensilely failed lava could have permitted noncondensed radionuclide gas to rise beyond the lava aquifer to the welded tuff aquifer. Enhanced contaminant transport under upward-flowing conditions (Brikowski, 1991) should be investigated.

Table 4. Phenomenological model for BENHAM.

\begin{tabular}{l|l|l}
\hline $\begin{array}{l}\text { Phenomenological } \\
\text { model component }\end{array}$ & \multicolumn{1}{|c|}{ Size } & \multicolumn{1}{|c}{ Permeability } \\
\hline \hline Puddle region & $8.05 \times 10^{5} \mathrm{Mg}$ glass over the lower cavity & Lower than pre-test \\
\hline Cavity region & 99 -m-radius sphere & Higher than pre-test \\
\hline Damage region & 297 -m-radius sphere & Higher than pre-test \\
\hline Chimney region & 99 -m-radius cylinder from working point to $640 \mathrm{~m}$ & Higher than pre-test \\
\hline
\end{tabular}

\subsection{TYBO}

Because the exact yield for TYBO is not announced, the calculated cavity radius and associated phenomenological model dimensions will vary with selected yields in the announced yield range as shown in Table 5.

Table 5. Variation in cavity radius over the announced yield range for TYBO.

\begin{tabular}{c|c}
\hline $\begin{array}{c}\text { Yield } \\
(\mathbf{k t})\end{array}$ & $\begin{array}{c}\text { Cavity radius using Eq. (1) } \\
(\mathbf{m})\end{array}$ \\
\hline 200 & 65.6 \\
\hline 500 & 89.1 \\
\hline 1000 & 112.2 \\
\hline
\end{tabular}




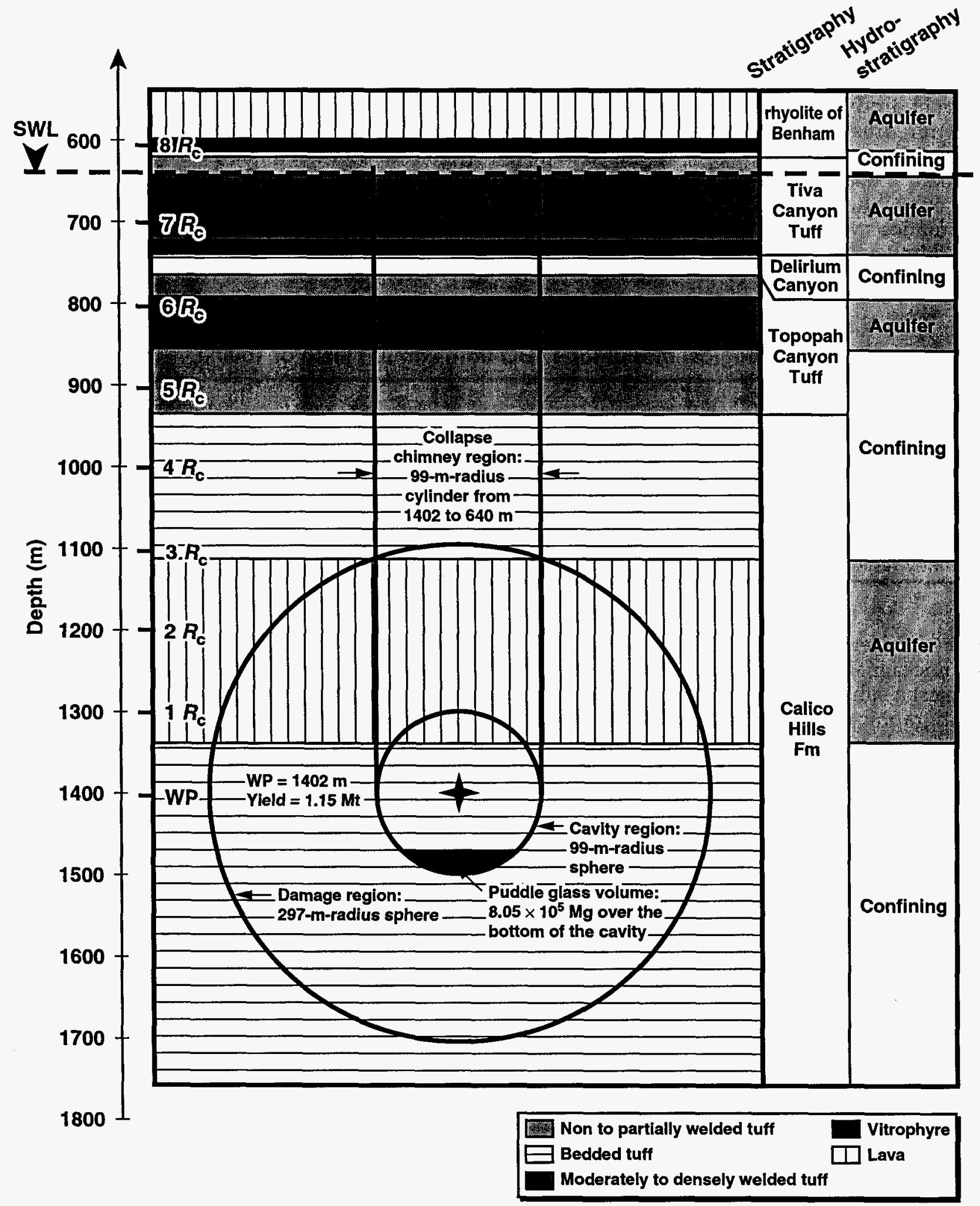

Figure 16. Phenomenological model for BENHAM. 
Table 6 summarizes geometries and suggests relative permeabilities for regions of the phenomenological model for TYBO at a maximum yield of $1000 \mathrm{kt}$. Because the unclassified yield for TYBO is not accurately known, the maximum of the announced yield range should be used to adequately represent the maximum possible volume affected by the test. The only site-specific information useful in constraining model geometries is the $200-\mathrm{m}$ radius calculated from hydrodynamic modeling for the tensilely failed region just below the water table. If a $200-\mathrm{m}$ radius at the water table is set, then the calculated damage region radius is 1.8 cavity radius. It seems reasonable to assume a damage region radius of $224 \mathrm{~m}$, or 2 cavity radii at $1000 \mathrm{kt}$. TYBO collapsed to the surface. The collapse chimney shown in Figure 17 was sketched by connecting the cavity sphere with crater edges at the ground surface. Since transport calculations will use the water table as a boundary, the upper portion of the damage region and the chimney region will not be part of the model. The TYBO phenomenological model is shown schematically in Figure 17.

Table 6. Phenomenological model for TYBO at maximum yield of 1000kt.

\begin{tabular}{|c|c|c|}
\hline $\begin{array}{l}\text { Phenomenological model } \\
\text { component }\end{array}$ & Size & Permeability \\
\hline Puddle region & $7.0 \times 10^{5} \mathrm{Mg}$ glass over the lower cavity & Lower than pre-test \\
\hline Cavity region & 112-m-radius sphere & Higher than pre-test \\
\hline Damage region & 224-m-radius sphere & Higher than pre-test \\
\hline Chimney region & Outside of saturated area & $\mathrm{n} / \mathrm{a}$ \\
\hline
\end{tabular}

Still of concern are the lineations near the TYBO SGZ formed during collapse and the anomalous seismic signals from both BENHAM and TYBO. The linearity and length of these features suggest a subsurface structure. However, surface-velocity data shown in Figure 11 and recent stratigraphic correlation by Prothro and Warren (1999) indicate a lack of major geologic structure between the TYBO and BENHAM sites. The high ground motion from TYBO can be explained by focusing off the water table. However, seismic data from both BENHAM and TYBO appear anomalous to some degree, and this has yet to be reconciled. 


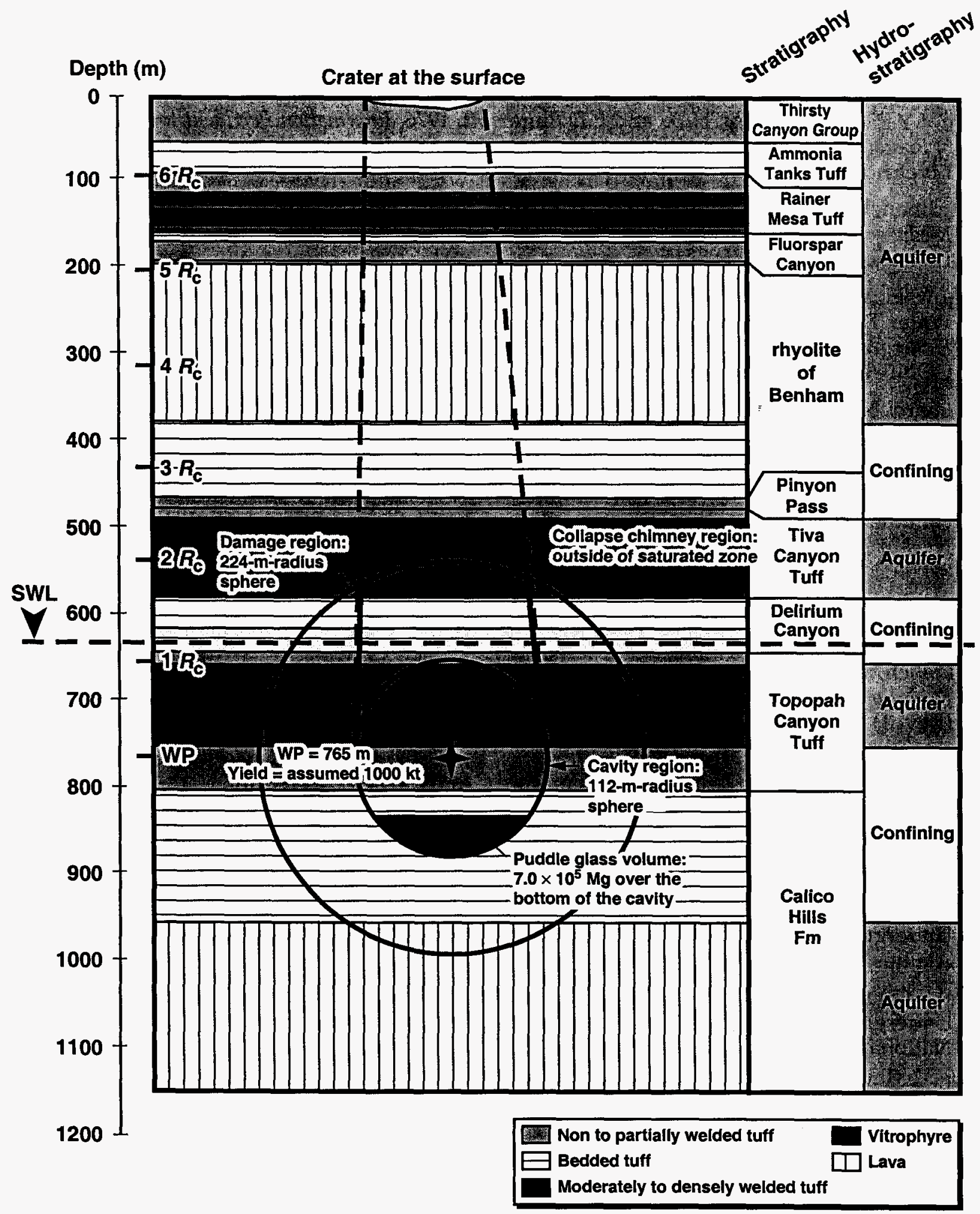

Figure 17. Phenomenological model for TYBO at maximum announced yield. 


\subsection{References}

Borg, I.Y., 1973. "Extent of Pervasive Fracturing around Underground Nuclear Explosions," Inter. J. Rock Mechanics Mineral Sci. 10.

Borg, I.Y., Stone, R., Levy, H.B., and L.D.Rampsott, 1976, Information Pertinent to the Migration of Radionuclides in Ground Water at the Nevada Test Site, Lawrence Livermore Laboratory, Livermore CA, UCRL-52078 Part 1.

Boardman, C.R., Rabb, D.D., and R.D. McArthur, 1964. Contained Nuclear Detonations in Four Media - Geologic Factors in Cavity and Chimney Formation, Livermore Radiation Laboratory, Livermore, CA, UCRL-7711.

Brikowski, T., 1991. "Estimation of Hydrologic Transport of Radionuclides from below the Water Table Using Analytic Models," in Proc. of the 6th Symp. on Containment of Underground Nuclear Explosions, Lawrence Livermore National Laboratory, Livermore, CA, CONF-9109114, Vol. 2.

Burkhard, N.R., and J.T. Rambo, 1991. "One Plausible Explanation for Water Mounding," in Proc. of the 6th Symp. on Containment of Underground Nuclear Explosions, Lawrence Livermore National Laboratory, Livermore, CA, CONF-9109114, Vol. 2.

Burkhard, N.R., Hearst, J.R, and Hanson, J.M., 1987. "Estimation of Bulk Diffusivity of Chimneys Using Post-Shot Holes", in Proc. of the 4th Symp. on Containment of Underground Nuclear Explosions, Lawrence Livermore National Laboratory, Livermore, CA, CONF870961, Vol. 2.

Butkovich, T.R., 1976. Cavities Produced by Underground Nuclear Explosions, Lawrence Livermore National Laboratory, Livermore, CA, UCRL-52097.

Butkovich, T.R., and A.E. Lewis, 1973. Aids for Estimating Effects of Underground Nuclear Explosions, Lawrence Livermore National Laboratory, Livermore, CA, UCRL-50929 (Rev. 1).

Butkovich, T.R., and J.R. Hearst, 1976. Prediction and Determination of Explosive-Induced Fracture, Lawrence Livermore Laboratory, Livermore CA, UCRL-77659 Preprint.

Carroll, R.D., 1981. "Seismic Velocity and Postshot Properties in and near Chimneys," in Proc. of the Monterey Containment Symposium, Los Alamos National Laboratory, Los Alamos, NM, LA-9211-C, Vol. 1.

Cizek, J.C., and A.L. Florence, 1981a. "Laboratory Investigation of Containment of Underground Nuclear Explosions," in Proc. of the Monterey Containment Symposium, Los Alamos National Laboratory, Los Alamos, NM, LA-9211-C, Vol. 1.

Cizek J.C., and A.L. Florence, 1981b. "Dynamic Effect of Structure on Containment of Underground Explosions," in Proc. of the Monterey Containment Symposium, Los Alamos National Laboratory, Los Alamos, NM, LA-9211-C, Vol. 1.

Dudley, W.W., 1972. USGS informal letter to Richard McArthur of Lawrence Livermore National Laboratory on water levels at U20y, dated July 28, 1972.

Environmental Research Corporation, 1968. Summary Report of Predictions Benham Event (title unclassified).

Germain L.S., and J.S. Kahn, 1968. Phenomenology and Containment of Underground Nuclear Explosions, Lawrence Livermore National Laboratory, Livermore, CA, UCID-50482. 
Griffiths, S.K., and R.H. Nilson, 1987. "Similarity Analysis of Condensing Flow in a Fluid Driven Fracture," in Proc. of the 4th Symp. on Containment of Underground Nuclear Explosions, Lawrence Livermore National Laboratory, Livermore, CA, CONF-870961, Vol. 1.

Hamilton, R.M., F.A. McKeown, and J.H. Healy, 1969. "Seismic Activity and Faulting Associated with a Large Underground Nuclear Explosion," Science 166, 601-604.

Higgins, G.H., 1987. "Shock Vaporation and Melting of Saturated Tuff," in Proc. of the 4th Symp. on Containment of Underground Nuclear Explosions, Lawrence Livermore National Laboratory, Livermore, CA, CONF-870961, Vol. 1.

Howard, N., 1981. U20ag Preliminary Site Characteristics Summary, Lawrence Livermore National Laboratory, Livermore, CA, internal memorandum dated October 2, 1981.

Hudson, B.,S. Pratuch, R. Heinle, M. Hatch, and T. Stubbs, 1993. "GALENA Pressure History and a Proposed Sensor for Mean Residual Stress," in Proc. of the 7th Symp. on Containment of Underground Nuclear Explosions, Lawrence Livermore National Laboratory, Livermore, CA, CONF-9309103, Vol. 1.

Hudson, B.C., 1981. "Cavity Radius Uncertainties," in Proc. of the Monterey Containment Symposium, Los Alamos National Laboratory, Los Alamos, NM, LA-9211-C, Vol. 1.

Kenneally, J., 1996. Post-Shot Drilling Gamma-Log Investigation to Assess the Distribution of Radionuclides In and Around Expended Underground Nuclear Test Cavities, Lawrence Livermore National Laboratory, Livermore, CA, internal report.

Kersting, A.B., 1996. The State of the Hydrologic Source Term, Lawrence Livermore National Laboratory, Livermore, CA, UCRL-ID-126557.

Kersting, A.B., D.W. Efurd, D.L. Finnegan, D.J. Rokop, D.K. Smith, and J.L Thompson, 1999. "Migration of Plutonium in Groundwater at the Nevada Test Site,"Nature 397, 56-59.

Knox, J.B., D.E. Rawson, and J.A. Korver, 1965. "Analysis of a Groundwater Anomaly Created by an Underground Nuclear Explosion," J. Geophys. Res. 70(4).

Kunkle, T.D., and B.J. Travis, 1981. "Hydrofracture from a Growing Cavity," in Proc. of the Monterey Containment Symposium, Los Alamos National Laboratory, Los Alamos, NM, LA-9211-C, Vol. 1.

Martin, J.W., J.T. Fredrich, and S.J. Green., 1993. "Recent Observations of Mechanical Properties and Microstructure of Shock-Conditioned Tuff," in Proc. of the 7th Symp. on Containment of Underground Nuclear Explosions, Lawrence Livermore National Laboratory, Livermore, CA, CONF-9309103, Vol. 2.

McKague, H.L., 1975. Site Characteristics Summary of U2Oy, Lawrence Livermore National Laboratory, Livermore, CA, internal report UOPKB 75-28.

McKague, H.L., E. Kansa, P.K. Kasameyer, and R.F. Corwin, 1991. “Detecting and Modeling Persistent Self-Potential Anomalies from Underground Nuclear Explosions at the Nevada Test Site," in Proc. of the 6th Symp. on Containment of Underground Nuclear Explosions, Lawrence Livermore National Laboratory, Livermore, CA, CONF-9109114, Vol. 2.

Newmark, R.L., and J.L. Wagoner, 1990. U20bb Site Characteristics Report, Lawrence Livermore National Laboratory, Livermore, CA, internal memorandum dated April 13, 1990.

Nilson, R., N. Rimer, and E. Halda, 1987. "Simultaneous Modeling of Dynamic Ground Motion and Fluid Flow in Hydrofractures," in Proc. of the 4th Symp. on Containment of Underground Nuclear Explosions, Lawrence Livermore National Laboratory, Livermore, CA, CONF-870961, Vol. 1. 
Nilson, R.H., 1981. "Fluid/Thermal Analysis of Steam-Driven Fracture Propagation from a Nuclear Cavity," in Proc. of the Monterey Containment Symposium, Los Alamos National Laboratory, Los Alamos, NM, LA-9211-C, Vol. 1.

Nilson, R.H., E.J. Halda, and S.K. Griffiths, 1991. "Sustained Growth of Multiple Gas-Driven Fractures," in Proc. of the 6th Symp. on Containment of Underground Nuclear Explosions, Lawrence Livermore National Laboratory, Livermore, CA, CONF-9109114, Vol. 1.

Nimz, G.J., and J.L. Thompson, 1992. Underground Radionuclide Migration at the Nevada Test Site, U.S. Department of Energy, Nevada Field Office, DOE/NV-246, UC-703.

Olsen, C.W., 1993. "Site Selection and Containment Evaluation for LLNL Nuclear Events," in Proc. of the 7th Symp. on Containment of Underground Nuclear Explosions, Lawrence Livermore National Laboratory, Livermore, CA, CONF-9309103 Vol. 1.

Peterson, E., K. Lie, N. Rimer, and R. Nilson, 1991. "Thermodynamic Evolution of Nuclear Cavities," in Proc. of the 6th Symp. on Containment of Underground Nuclear Explosions, Lawrence Livermore National Laboratory, Livermore, CA, CONF-9109114, Vol. 1.

Peterson, E., Lagus, P., and K. Lie, 1978. Summary of the MING BLADE Tracer-Gas Chimney Pressurization Studies, Systems, Science, and Software report, SSS-R-78-3535.

Peterson, E., Lagus, P., and K. Lie, 1977. Summary of the DINING CAR Tracer-Gas Chimney Pressurization Studies, Systems, Science, and Software report, SSS-R-77-3185.

Piwinskii, A.J., F.J. Ryerson, and W.F. Beiriger, 1983. "A Chemical Investigation of glasses Produced by the RAINIER Underground Explosion," in Proc. of the 2nd Symp. on Containment of Underground Nuclear Explosions, Lawrence Livermore National Laboratory, Livermore, CA, CONF-830882, Vol. 1.

Prothro, L.B., and R.G. Warren, 1999. Geology in the Vicinity of the TYBO and BENHAM Underground Nuclear Tests, Pahute Mesa, Nevada Test Site, Bechtel Nevada report, DOE/NV/11718-305.

Rambo, J.T., 1987. "Geologic and Material Property Combinations that Adversely Influence Residual Stress in 2-D Dynamic Containment Calculations," in Proc. of the 4th Symp. on Containment of Underground Nuclear Explosions, Lawrence Livermore National Laboratory, Livermore, CA, CONF-870961, Vol. 1.

Rambo, J.T., and J. Bryan, 1983. Calculation of High Surface Velocity due to Focusing on the TYBO Event $(U)$, Lawrence Livermore National Laboratory, Livermore, CA, UCRL-89405 Preprint.

Rambo, J.T., and N. Rimer, 1993. "Calculations of NTS Residual Stress Measurements and Some Implications for Models and Material Properties," in Proc. of the 7th Symp. on Containment of Underground Nuclear Explosions, Lawrence Livermore National Laboratory, Livermore, CA, CONF-9309103, Vol. 1.

Rambo, J.T., and W.C. Moss, 1991. "BARNWELL Residual Stress Simulations: The Tuned Hard Rock Scenario (U)," in Proc. of the 6th Symp. on Containment of Underground Nuclear Explosions (U), Lawrence Livermore National Laboratory, Livermore, CA, CONF-9109114, Vol. 3.

Rimer, N., 1981. "Medium Property Effects on Containment," in Proc. of the Monterey Containment Symposium, Los Alamos National Laboratory, Los Alamos, NM, LA-9211-C, Vol. 1.

Rimer, N., R. Nilson, E. Halda, and K. Lie, 1987. "Recent Developments in Hydrofracture Calculations Related to Containment," in Proc. of the 4th Symp. on Containment of Underground Nuclear Explosions, Lawrence Livermore National Laboratory, Livermore, CA, CONF-870961, Vol. 1. 
Rozsa, R., Snoeberger, D., and Baker, J., 1975, Permeability of a nuclear Chimney and Surface Alluvium, Area 2, ERDA NTS, Lawrence Livermore Laboratory, UCID-16722

Smith, C.W., 1981. "Contained Nuclear Explosion Models," in Proc. of the Monterey Containment Symposium, Los Alamos National Laboratory, Los Alamos, NM, LA-9211-C, Vol. 1.

Smith, C.W., and S.P. Breeze, 1993. "Cavity Gas Pressure Measurements on DIAMOND FORTUNE," in Proc. of the 7th Symp. on Containment of Underground Nuclear Explosions, Lawrence Livermore National Laboratory, Livermore, CA, CONF-9309103, Vol. 1.

Smith, D.K., 1995. Phenomenology of Underground Nuclear Explosions Conducted at the Nevada Test Site with Emphasis on Recent Experience at BASEBALL (U7ba) and INGOT (U2gg), Lawrence Livermore National Laboratory internal memo dated September 6, 1995.

Terhune, R.W., and H.D. Glenn, 1977. Estimate of Earth Media Shear Strength at the Nevada Test Site, Lawrence Livermore National Laboratory, Livermore, CA, UCRL-52358.

Terhune, R.W., H.D. Glenn, D.E. Burton, H.L. McKague, and J.T. Rambo, 1977. Calculational Examination of the BANEBERRY Event, Lawrence Livermore National Laboratory, Livermore, CA, UCRL-52365.

Thompson, J.L., 1998. Laboratory and Field Studies Related to Radionuclide Migration at the Nevada Test Site, October 1, 1996-September 30, 1997, Los Alamos National Laboratory, Los Alamos, MN, LA-13419-PR Progress Report.

Tompson, A.F.B., Carol Bruton, and G. Pawloski, Editors, 1999. Evaluation of the Hydrologic Source Term from Underground Nulcear Tests in Frenchman Flat at the Nevada Test Site: The CAMBRIC Test, Lawrence Livermore National Laboratory, Livermore, CA, UCRL-ID132300.

Toman, J., 1975. "Production Test Data and Preliminary Analysis of Top Chimney/Cavity," Nuc. Tech. 27, 692-704.

Townsend, Dean, 1994. RED HOT Reentry - A Report on the Results of Four Phases of Reentry Mining and Drilling Conducted by the Defense Nuclear Agency Between 1981 and 1985. Raytheon Services Nevada report, TSP:DGP:066:95.

U.S. Congress/Office of Technology Assessment, 1989. The Containment of Underground Nuclear Explosions, PB90-1561183.

U.S. Department of Energy, 1994. United States Nuclear Tests-July 1945 through September 1992, DOE/NV-209 Rev. 14.

U.S. Department of Energy, 1997. Completion Report for ER-20-5, Nevada Environmental Restoration Project, DOE/NV-466 UC-700.

Wadman, R.E., and W.D. Richards, 1961. Postshot Geologic Studies of Excavations below Rainier Ground Zero, Lawrence Livermore National Laboratory, Livermore, CA, UCRL-6586. 


\subsection{Acknowledgments}

Data on underground nuclear tests was acquired and archived by the Lawrence Livermore National Laboratory weapons testing program, including the Defense and Nuclear Technology Directorate's Containment Program. My sincere thanks to John Rambo, who has provided much guidance to me as a Containment Scientist.

This work was funded by the Underground Test Area Project, U.S. Department of Energy, Nevada Operations Office, and performed under the auspices of the U. S. Department of Energy by the University of California, Lawrence Livermore National Laboratory under Contract No. W-7405-Eng-48. 
University of California

Lawrence Livermore National Laboratory

Technical Information Department

Livermore, CA 94551

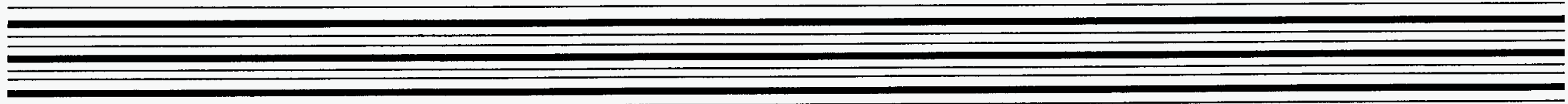

